The University of Maine

DigitalCommons@UMaine

Electronic Theses and Dissertations

Fogler Library

$12-2013$

\title{
A Model Study of the Copper River Plume and its Effects on the Northern Gulf of Alaska
}

Yuan Wang

Follow this and additional works at: http://digitalcommons.library.umaine.edu/etd

Part of the Oceanography Commons

\section{Recommended Citation}

Wang, Yuan, "A Model Study of the Copper River Plume and its Effects on the Northern Gulf of Alaska" (2013). Electronic Theses and Dissertations. 2017.

http://digitalcommons.library.umaine.edu/etd/2017

This Open-Access Thesis is brought to you for free and open access by DigitalCommons@UMaine. It has been accepted for inclusion in Electronic Theses and Dissertations by an authorized administrator of DigitalCommons@UMaine. 


\title{
A MODEL STUDY OF THE COPPER RIVER PLUME AND ITS EFFECTS \\ ON THE NORTHERN GULF OF ALASKA
}

\author{
By \\ Yuan Wang \\ B.S. University of Science and Technology of China, 2010 \\ A THESIS \\ Submitted in Partial Fulfillment of the \\ Requirements for the Degree of \\ Master of Science \\ (in Oceanography)
}

The Graduate School

The University of Maine

December 2013

Advisory Committee:

Huijie Xue, Professor of Oceanography, Co-Advisor

Fei Chai, Professor of Oceanography, Co-Advisor

Andrew Thomas, Professor of Oceanography 


\title{
A MODEL STUDY OF THE COPPER RIVER PLUME AND ITS EFFECTS \\ ON THE NORTHERN GULF OF ALASKA
}

\author{
By Yuan Wang \\ Thesis Advisor: Dr. Huijie Xue \\ An Abstract of the Thesis Presented \\ in Partial Fulfillment of the Requirements for the \\ Degree of Master of Science \\ (in Oceanography) \\ December 2013
}

Using a three-level nested Regional Ocean Modeling System coupled with the Carbon, Silicate, Nitrogen Ecosystem model, this study examined the seasonal evolution of the Copper River (CR) plume and how it influences the along- and across-shore transport in the northern Gulf of Alaska (NGoA). A passive tracer was introduced in the model to delineate the growth and decay of the plume and to diagnose the spread of the CR discharge in the shelf, into Prince William Sound (PWS) and offshore.

Furthermore, a model experiment with doubled discharge was conducted to investigate potential impacts of accelerated glacier melt in future climate scenarios.

The 2010 and 2011 simulation revealed that the upstream (eastward) transport in the NGoA is almost nil. About $60 \%$ of the passive tracer released in the CR discharge is transported southwestward on the shelf, while another one third goes into PWS with close to $60 \%$ of which exiting PWS to the shelf from Montague Strait. The rest few percent is transported across the shelf break and exported to the GoA basin. The downstream transport and the transport into PWS are regulated by the downwelling- 
favorable wind, while the offshore transport is related to the accumulation of plume water in the shelf, frontal instability and the Alaskan Stream. The CR plume appears to decay much faster than its formation. It takes weeks for the buoyancy to accumulate so that a bulge forms outside of the CR estuary. If the wind remains calm as in the summer of 2010 , the bulge continues growing to trigger frontal instability. These frontal features can interact with the Alaskan Stream to send intense transport pulses across the shelf break. Alternatively as in 2011, a downwelling-favorable wind event in early August (near the peak discharge) accelerates the southwestward coastal current and produces an intense downstream transport event. Both processes result in fast drains of the buoyancy and the plume content, thereby rapid disintegration of the plume in the shelf. The plume in the doubled discharge case can be 2-3 times in size, which affects not only the magnitude but also the timing of certain transport events. In particular, the offshore transport increases by several folds because the plume appears to be more easily entrained by the seaward flow along the side of Hinchinbrook Canyon. 


\section{DEDICATION}

I would like to dedicate this work to my beloved wife Xiaoyi whose love and companionship has been inspiring me for diligent exploration in life; and to my parents, Xiaochun Yue and Jianzhong Wang, who open the marvelous world to me and their everlasting love and support is the breeze that relieves me from fear and weariness on every new journey. 


\section{ACKNOWLEDGEMENTS}

I would like to thank everyone who helped me during my Mater of Science, in particular my advisors: Dr. Huijie Xue for the knowledge she shared with me through her patient dedicated supervision and Dr. Fei Chai for his valuable wisdom and encouragement. I also thank my committee Andrew Thomas for his valuable comments and the inspiration. I should thank Steve Cousins, who is a kind hearted and knowledgeable computer specialist and helped me a lot on data conversion and technical support for using the cluster. I am grateful to many faculty members, Emmanuel Boss, Peter A. Jumars, Larry Mayer, Mary Jane Perry, Daniel Belknap, Qingpin Zou, and Yifeng Zhu, whose classes I was fortunate to attend at the University of Maine. I should thank Jeff Runge and everyone who shared their knowledge and happiness with me on ocean acidification cruise. I am grateful to Sue Thibodeau, Jodie Feero, William Ellis and all the members of the School of Marine Sciences office who helped me in many ways throughout my graduate studies. They never hesitated to offer their help whenever I needed it. I am indebted to them for their invaluable support.

Thanks other project collaborators, John Crusius, Rob Campbell and Andrew

Schroth for providing the observation data used in this study; Thanks Chao Yi and John Farrara for sharing their reanalysis precipitation data to me and help me validate my model. I also appreciate Tom Weingartner, Seth Danielson and David Leech for maintaining and sharing GAK1 data. Last but not least, this work was supported by the U.S. Geological Survey (USGS). 


\section{TABLE OF CONTENTS}

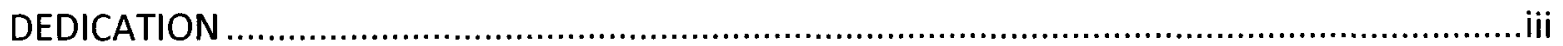

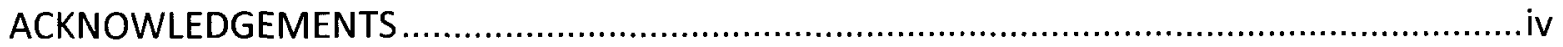

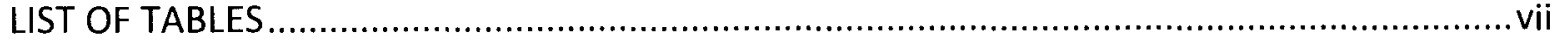

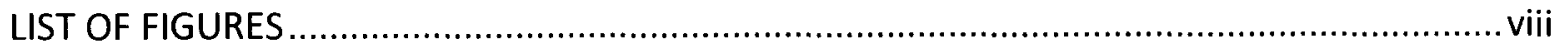

\section{CHAPTER}

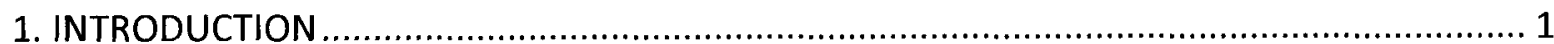

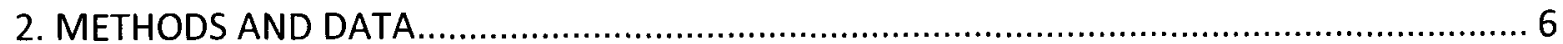

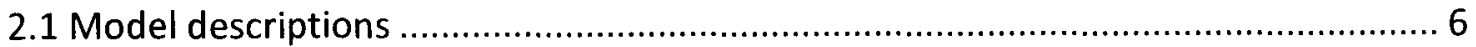

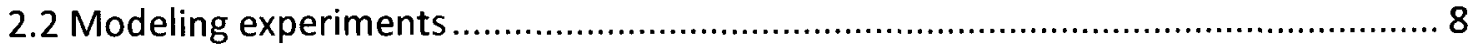

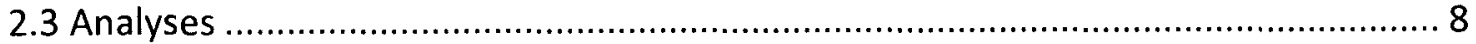

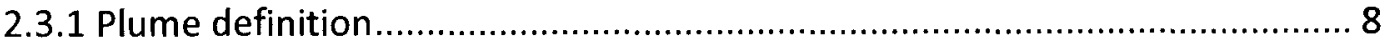

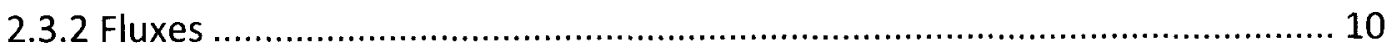


3.1 Comparison with observations

3.1.1 GAK1 time series

3.1.2 Cruise CTD casts

3.2 The CR plume evolution

3.3 CR plume and the along- and cross-shore transport in NGoA 28

3.4 The effect of the CR discharge on transport variability in X2 case. 36

4. CONCLUSIONS 44

REFERENCES 48

BIOGRAPHY OF THE AUTHOR 52 


\section{LIST OF TABLES}

Table $3.1 \quad$ Eleven CTD cruises in 2010 and 2011...................................................13 


\section{LIST OF FIGURES}

Figure 1.1 Satellite (MODIS on Terra) imagery of the NGoA on 17 June 2013............4

Figure 2.1 The two-year (2010 - 2011) mean surface circulation from the

WR case

Figure 3.1 Comparisons of the salinity and temperature between the model

and GAK1 Mooring .15

Figure 3.2 Comparisons between the model and CTD cruise No.4.

Figure 3.3 Taylor diagram to compare the model simulation with the CTD casts from 11 cruises in 2010 and 2011 20

Figure 3.4 Time series of the Copper River discharge, plume volume, total content of the passive tracer in the plume and the alongshore wind stress in $2010-2011$ 22

Figure 3.5 Plume occurrence frequency and the associated plume depth.................25

Figure 3.6 Plume maximum $\mathrm{N}^{2}$ and its associated depth. 26

Figure 3.7 Yearly integrated fluxes of the passive tracer at selected transects normalized to the river input in 2010 -2011, respectively. .30

Figure 3.8 Time series of the downstream transport at P2 and the transport into PWS at S1, offshore transport at OP and the distance from the $1 \mathrm{mmol} \mathrm{m}{ }^{-3}$ passive tracer concentration contour line to the offshore transect OP .31

Figure 3.9 Snapshots of the passive tracer distribution in the NGoA .34 
Figure 3.10 Comparison of along-and cross-shore transports between the $\mathrm{X} 2$

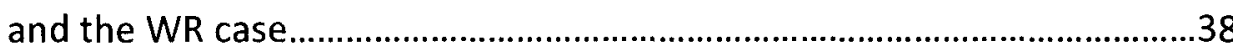

Figure 3.11 Time series for 2010 and 2011 in the X2 case, the river discharge and the plume volume, the downstream transport at P2 and the transport into PWS at S1, the offshore transport at OP and the distance from the $1 \mathrm{mmol} \mathrm{m}^{-3}$ passive tracer concentration contour line to the offshore transect OP

Figure 3.12 Snapshots of the passive tracer distribution in the $\mathrm{X} 2$ case .....................40 


\section{CHAPTER 1}

\section{INTRODUCTION}

The Northern Gulf of Alaska (NGoA) is bounded by the mountainous coast of Alaska to the north and east. Mountains of more than $5000 \mathrm{~m}$ elevated lie less than $50 \mathrm{~km}$ from the shore. Storms and elevation result in high precipitation rate on the order of $2-3 \mathrm{~m} \mathrm{yr}^{-1}$ in the coastal mountains, and much of the precipitation falls as snow (Royer 1982), leading to the formation of an extensive cool-temperate glacial setting (Powell and Molnia 1989). Coupling with the predominant downwelling-favorable wind in this area, the freshwater input from the coast drives the strong southwestward flowing Alaska Coastal Current (ACC), which dominates the circulation in the shelf and controls the transport of dissolved substances and planktonic materials (Stabeno et al. 1995a, b; Royer 1981). The northern boundary of the eastern subarctic gyre (the Alaskan Stream (AS)) dominates the current seaward of the shelf break (Ladd et al., 2005). The Gulf of Alaska now suffers an alarming recession of glaciers (Arendt et al. 2002; Luthcke et al. 2008). Climate models predict up to a $40 \%$ increase in river discharge from Alaska by 2050 (Milly et al. 2005). The profound changes on timing and magnitude of the freshwater input could significantly change not only the river runoff but also the riverine particulate and nutrient fluxes.

The Copper River (CR), fed by many glacial streams from the surrounding mountains, is the largest single freshwater source to the Gulf in the NGoA with the 
discharge ranging from $300 \mathrm{~m}^{3} \mathrm{~s}^{-1}$ in winter to as much as $8000 \mathrm{~m}^{3} \mathrm{~s}^{-1}$ during summer peaks. The CR drainage basin is comprised of many small ones of which the majority are glaciated (Alison et al. 2003). Hallet et al. (1996) found that the mountains in southern coastal Alaska have the highest rates of erosion in the world, exceeding $10 \mathrm{~mm} \mathrm{yr}^{-1}$, and the sediment loading of the $C R$, one of the 20 largest in the world, reaches 70 million tons $\mathrm{yr}^{-1}$ (Milliman and Meade 1983). These fine particles are an important source of reactive iron to the NGoA (Schroth et al. 2009). However, the nitrate concentration in the CR runoff is too low for the CR to be an important source of terrestrially derived nitrate to the NGoA (Hood et al. 2008). On the other hand, much of the Gulf of Alaska (GoA) basin is a "high-nutrient, low-chlorophyll" (HNLC) region, with abundant nitrate year-round, whereas phytoplankton productivity is iron-limited (Boyd et al. 2004). The GoA is thus the main source of nitrate to the nearshore GoA, which is nitrogen-limited (Childers et al. 2005). Consequently, it has been hypothesized that river-derived iron may play a significant role in stimulating the productivity of Northern Pacific shelf ecosystems (Chase et al. 2007).

Very little is known about the CR Plume and its variability for the lack of in situ observations limited by its remoteness. In 2010 and 2011, an interdisciplinary study funded by the U.S. Geological Survey (USGS) conducted spring-summer surveys of the CR and the nearby coastal region. As a part of this study, a coastal circulation model coupled with a biogeochemical model was developed to simulate the CR plume, determine the alongshore and offshore transport of riverine materials, as well as understand how the CR affects the ecosystem in the NGoA and how the CR's role might 
change in the light of anticipated climate changes. The model results show that the $C R$ plume contributes significant variability to the ACC not only near the CR estuary but also downstream at GAK1. Hence the knowledge of the CR plume and the related transports also helps to optimize the ACC monitoring and to better interpret archived data from the long-term hydrographic station GAK1.

The classic model of river discharge meeting the ocean has the outflow turn to the right in the northern hemisphere with a narrow coastal current that is trapped within a few internal Rossby radius typically on the order of a few kilometers in coastal oceans (Garvine 1999). A bulge-like region that accumulates river discharge is also noticed near the river mouth (Kourafalou et al. 1996; Thomas and Weatherbee 2005; Xue and $\mathrm{Du}, 2010$ ) and can extend over to the shelf break for big rivers such as the Columbia (Hickey et al. 2005), Mississippi (Schiller 2011) and Congo (Denamiel 2013). Numerical studies indicate that the growth and movement of the bulge is affected by the property of the outflow (Yankovsky and Chapman 1997; Avicola and Huq 2003a, b), the ambient coastal current (Fong and Geyer 2002) and the wind (Whitney and Garvine 2005).

In the NGoA, more than three fourths of the annual discharge is delivered from May to September. Meanwhile, the predominant downwelling-favorable wind relaxes and intermittent upwelling-favorable wind events take place. Both the increasing discharge and the upwelling-favorable wind favor the growth in volume and offshore spreading of the plume, which promotes the offshore transport of riverine materials. Satellite images also support this derivation. (Figure 1.1) In order to quantitatively 


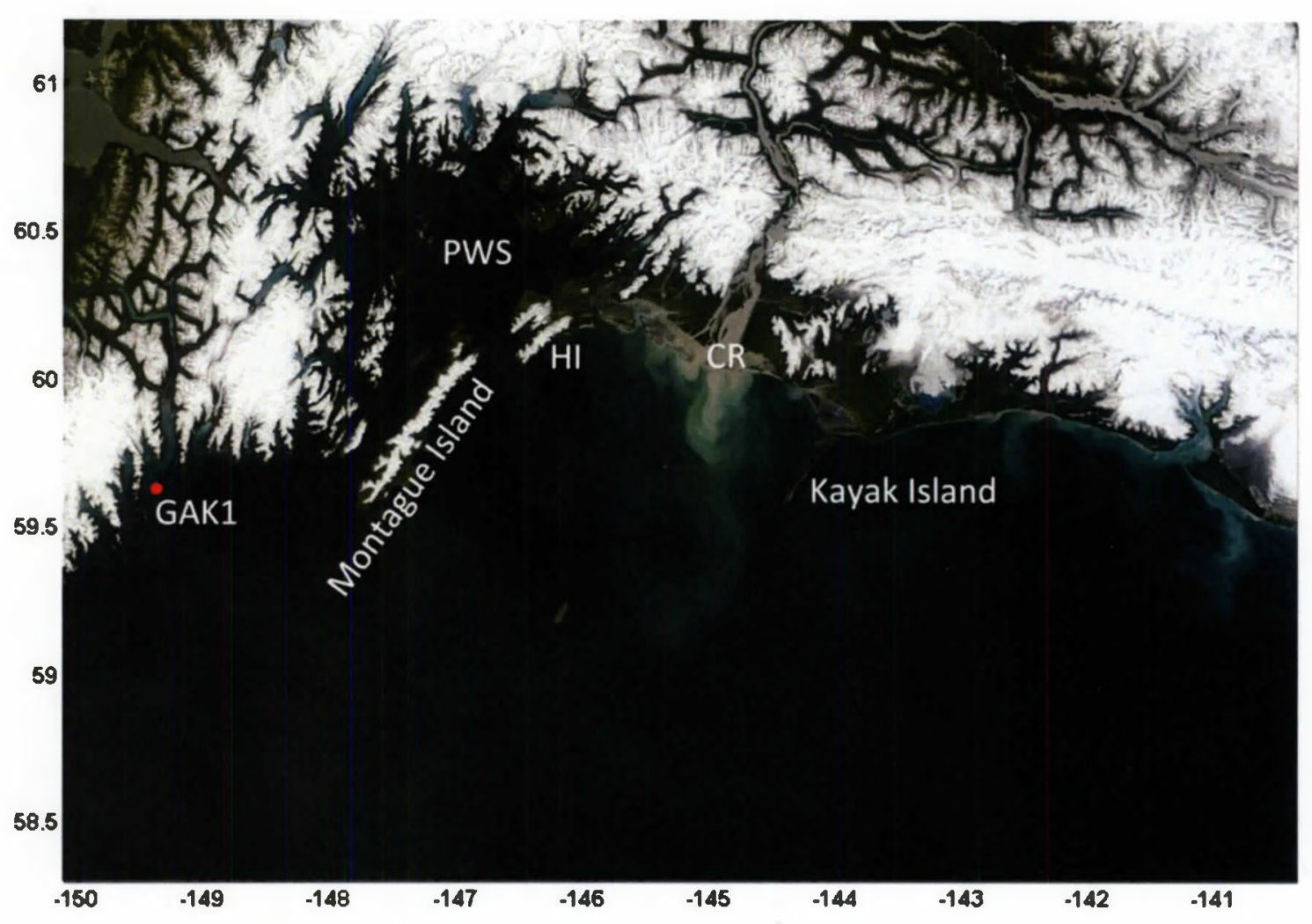

Figure 1.1 Satellite (MODIS on Terra) imagery of the NGoA on 17 June 2013

(http://earthobservatory.nasa.gov/IOTD/view.php?id=81416). CR indicates the mouth of the CR, PWS represents Prince William Sound, and HI indicates the Hinchinbrook Island. The red dot marks the location of a long-term hydrographic station GAK1. 
evaluate the effect of the CR in the NGoA and to estimate the implication associated with potential climate changes, this study entails the first numerical model study of the CR plume, focusing on the transport of riverine materials and its variability in timing and magnitude in 2010 and 2011. In addition, a hypothetical case of doubling the discharge is also examined. The model, data and numerical experiments are described in chapter 2 , followed by comparisons with the observations, evolution of the plume and the along/off-shore transport in chapter 3 . The conclusions of the study are presented in chapter 4 , respectively. 


\section{CHAPTER 2}

\section{METHODS AND DATA}

\subsection{Model descriptions}

The physical model we used is the three-level, one-way nested, Regional Ocean Model System (ROMS) (details in Chao et al. 2009; Farrara, 2011), with the finest grid resolution of about $1 \mathrm{~km}$ in Prince William Sound (PWS), west of the CR estuary. The one-way nested approach uses coarse-resolution grids to provide boundary conditions to the next-level, finer-resolution model without feedbacks from the finer-resolution model to the coarse-resolution model (in sequence, grid levels from the coarsestresolution, outermost grid to the finest, innermost grid are called level 0 , level 1 , and level 2). However, the level 2 grid doesn't cover the whole CR plume. We thus focus on level $1\left(54.9-61.8^{\circ} \mathrm{N}, 155.5-140^{\circ} \mathrm{W}\right)$ with overall $3.6 \mathrm{~km}$ horizontal resolution and 40 terrain following sigma-levels in the vertical direction. Tide and sea ice are not included in this study. Lateral open boundaries for level 0 are on the southern boundary and part of the western boundary, which are set as climatology. The vertical mixing parameterization scheme is K-Profile Parameterization (Large et al., 1994). The horizontal viscosity and tracer diffusivity are 100 and $20 \mathrm{~m}^{2} \mathrm{~s}^{-1}$, respectively.

In this study, other than the discharge from the CR all the freshwater input from coast is converted to precipitation and distributed along coastline (Farrara, 2011), while the $C R$ is added as a point source of freshwater (volume and momentum), buoyancy (salinity and temperature) and nutrients. The river mouth depth is set to $10 \mathrm{~m}$, the 
minimum depth in the model. The total freshwater discharge from the CR to the NGoA is measured at the Million Dollar Bridge gauging station (station number 15214000, USGS, www.usgs.gov), of which daily discharge data covers the whole study period. However, the water temperature data of the CR discharge is unavailable. The monthly mean water temperature from the nearest Cordova station (station number 9454050 , NDBC of NOAA, www.ndbc.noaa.gov) is used to represent the water temperature of the CR discharge. As shown in table 3.1, the observed temperature in Cordova station is close to CTD measured temperature near the CR mouth but generally cooler in summer. However, the density is primarily determined by the salinity in this area (Royer 2005), the impact of such temperature bias should not be decisive. The salinity of the discharge is increased to 4-6 PSU to maintain the stability of the model in the high discharge months, while the default is 0 . Nitrate and silicate are added as constant concentrations of 4.5 and $65 \mathrm{mmol} \mathrm{m}^{-3}$, respectively, which are obtained from the mean of monthly sampling in the river and delta (data courtesy of Dr. Andrew Schroth, USGS).

We use the North American Mesoscale Forecast System (NAM) \#242 AWIPS Grid product that covers the entire study area with $11.25 \mathrm{~km}$ resolution and a full complement (wind speed, wind stress, air temperature, long-/short-wave radiation, relative humidity and precipitation) of surface atmospheric forcing (National Climate Data Center, www.ncdc.noaa.gov). The NAM is initialized with a $12-\mathrm{h}$ run of the NAM Data Assimilation System, which conducts a sequence of four Grid-Point Statistical Interpolation (GSI) analyses and 3-h WRF-NMM forecasts using all available observations 
to provide a first guess to the NAM "on-time" analysis and forecasts $84 \mathrm{~h}$ every $3 \mathrm{~h}$. We only use the $0-24 \mathrm{~h}$ (every 3 hours) forecast for more reliability.

\subsection{Modeling experiments}

We performed a realistic simulation over the two year period from 1 January 2010 to 31 December 2011 (designated as the "WR" case) and two sensitivity simulations: (1) without the CR discharge point source ("NR" case), and (2) double the CR discharge ("X2" case). The only difference between the WR case and two sensitivity simulations is the CR discharge, with which we can assess the effect of the CR discharge and the increasing discharge scenario for future projections related to climate change.

Freshwater in this area originates from four primary sources, namely, the $C R$, the precipitation, the Alaska Coastal Current, and PWS. In order to assess the effect of the CR discharge, in the model we added an inert tracer to the river discharge with a constant concentration of $100 \mathrm{mmol} \mathrm{m}^{-3}$. As it is controlled by physical processes only, the inert tracer is a useful indicator of how the freshwater from the CR is mixed and transported in the NGoA shelf.

\subsection{Analyses}

In this study, the model outputs are daily averages and all the analyses are based on this daily data.

\subsubsection{Plume definition}

The plume is a transition from the freshwater to the saline coastal water. The definition of the plume is important but diverse. In idealized modeling experiments and many occasions with only one primary freshwater source, either an isohaline is chosen 
to separate the plume from the ambient water (Hickey et al. 1998) or a certain salinity difference from the ambient water is chosen to characterize the plume (Geyer et al. 2004) or the salinity gradient is chosen to distinguish the river plume (Xue and Du, 2010). In this study, many other freshwater sources affect the salinity in the region including the ACC upstream (31.5 - 32.5 PSU), PWS (25 - 31 PSU), and the precipitation. For example, once the plume water enters the Hinchinbrook Entrance into PWS, neither the salinity nor the difference/gradient is able to characterize the CR plume.

In this study, the plume is primarily defined as the passive tracer concentration higher than or equal to $5 \mathrm{mmol} \mathrm{m}^{-3}$. The advantage of this definition is that it not only delineates the features (salt wedge, frontal zone, etc.) of the CR plume according to the theory as well as the annual cycle of the plume evolution but also distinguishes the CR plume from the freshwater pool from PWS, i.e., the outflow from PWS $(<30$ PSU and $<5$ $\mathrm{mmol} \mathrm{m}^{-3}$ ). After the delineation, different aspects of the plume can be quantified by treating the plume as a slab object. The occurrence frequency of the plume is the times when given grid point is occupied by the plume divided by the total number of days in the period over which the statistics are derived. Having the occurrence closer to 1 in a grid point indicates that the plume occurs more often at that location, and other plume properties (e.g., plume depth) are the averages in the days when the plume is present at that grid point. Wind stress is also averaged over the defined plume as to represent the wind imposed on the plume. As coastline here is curved but generally in zonal direction (east-west), zonal component of the wind stress is simply used to represent alongshore wind. 


\subsubsection{Fluxes}

Eight transects in the NGoA (Figure 2.1) are selected for analyzing the alongshore and offshore transport of the CR discharge in the northern shelf. The advection fluxes that are about three orders higher than the diffusion fluxes at these transects are calculated as:

$$
F=\iint_{-H}^{\eta} f(z, l) \cdot v_{n} d z d l
$$

Here, $F$ is the flux through a transect, $\eta$ is the surface elevation, $H$ is the depth of the water column, $v_{n}$ is the flow normal to the transect, and $f(z, l)$ is the property distribution at the transect. For the volume transport, $f(z, l)$ is 1 . 


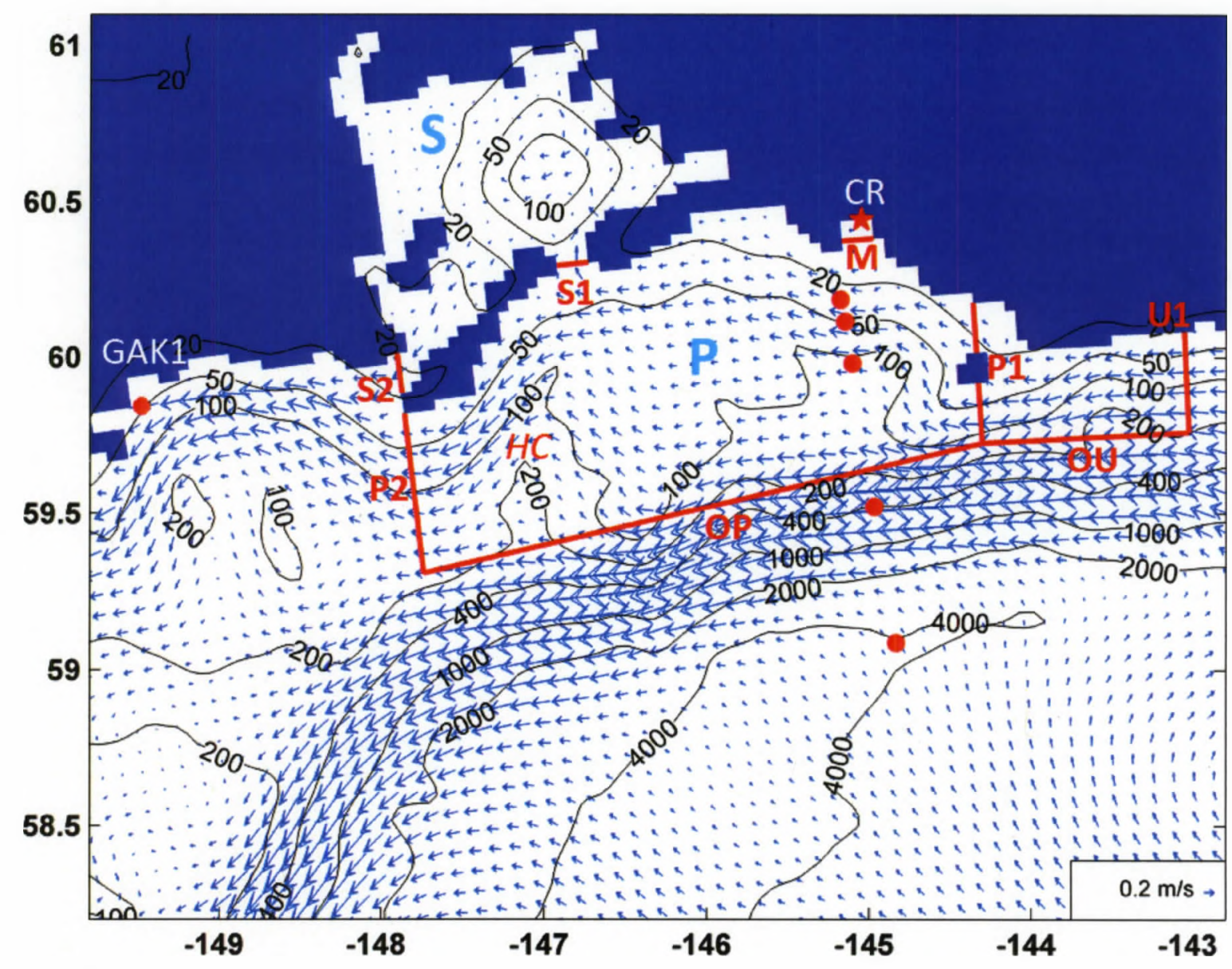

Figure 2.1 The two-year (2010 - 2011) mean surface circulation from the NR case. "CR" indicates the CR mouth; "GAK1" indicates the GAK1 station; "HC" indicates the Hinchinbrook Canyon; and the red dots represent the five CTD stations during the 2010 and 2011 field study. Also shown are eight transects selected to illustrate the along- and cross-shore transports presented in section 3.3 and 3.4 . 


\section{CHAPTER 3}

\section{RESULTS AND DISCUSSION}

Figure 2.1 shows the two-year mean surface circulation from the experiment WR. It agrees well with the general pattern of the coastal circulation in the NGoA (Hermann et al. 2002; Weingartner et al. 2005). Although the CR freshwater discharge peak is as high as $8000 \mathrm{~m}^{3} \mathrm{~s}^{-1}$, its mean of $1695 \mathrm{~m}^{3} \mathrm{~s}^{-1}$ in 2010 and 2011 is an order lower than that of the freshwater input into the ACC at $\sim 23,000 \mathrm{~m}^{3} \mathrm{~s}^{-1}$ (Royer, 1982). As a result, the differences in the mean coastal circulation between the NR and WR cases are subtle. The currents on the shelf generally flow westward. The ACC veers towards the shore east of the CR delta after it passes by Kayak Island, and then follows the $50 \mathrm{~m}$ isobath through the area directly impacted by the CR plume (see Figure 3.5 later). A part of the ACC enters PWS, but the majority meets with the branch steered by the Hinchinbrook Canyon from the Alaskan Stream to form the coastal jet flowing seaward of Montague Island. This latter eventually meets the outflow from PWS and flows by the station GAK1 near shore, as observation in station GAK1 is used to evaluate model performance at far downstream of the CR plume in chapter 3.1.1.

\subsection{Comparison with observations}

In-situ observations are sparse. CTD data from eleven dedicated cruises ( 4 in 2010 and 7 in 2011, Table 3.1) and time series of the temperature and salinity at GAK1 


\begin{tabular}{|c|c|c|c|c|}
\hline Cruise No. & Date & Bottom Depth (m) & $\begin{array}{l}\text { Nearest to } \mathrm{CR} \\
\text { mouth }\left({ }^{\circ} \mathrm{C}\right)\end{array}$ & $\begin{array}{c}\text { Cordova WT } \\
\left({ }^{\circ} \mathrm{C}\right)\end{array}$ \\
\hline 1 & $04 / 07 / 2010-04 / 09 / 2010$ & $17-4000 m$ & 4.7 & 4.9 \\
\hline 2 & $05 / 06 / 2010-05 / 07 / 2010$ & $18-4115 m$ & 6.5 & 6.9 \\
\hline 3 & $07 / 28 / 2010$ & $3-122 m$ & 10.8 & 11.3 \\
\hline 4 & $07 / 27 / 2010-07 / 29 / 2010$ & $14-4000 m$ & 12.3 & 10.2 \\
\hline 5 & $03 / 26 / 2011-03 / 28 / 2011$ & $20-4000 m$ & 3.7 & 4.2 \\
\hline 6 & $05 / 07 / 2011-05 / 08 / 2011$ & $20-4100 m$ & 5.8 & 5.8 \\
\hline 7 & $05 / 27 / 2011-05 / 28 / 2011$ & $6-144 m$ & 7.8 & 8.8 \\
\hline 8 & $06 / 16 / 2011$ & $100-140 m$ & Unavailable & 7.2 \\
\hline 9 & $06 / 28 / 2011-06 / 29 / 2011$ & $7-145 m$ & 11.5 & 9.6 \\
\hline 10 & $07 / 26 / 2011-07 / 27 / 2011$ & $19-4000 m$ & 13.3 & 12.4 \\
\hline 11 & $08 / 29 / 2011-08 / 30 / 2011$ & $9-142 m$ & 12.6 & 11.1 \\
\hline
\end{tabular}

Table 3.1 Eleven CTD cruises in 2010 and 2011. The last two columns are (1) the mean observed CTD temperature at the station that nearest to CR mouth, and (2) mean observed water temperature (hourly) in Cordova station at the same day. 
from the two years are used to compare with the model results in the NGoA. Cruise stations and the GAK1 mooring locations are marked in Figure 2.1. The five stations were not always repeated, but they were always in the vicinity of the marked locations.

\subsubsection{GAK1 time series}

GAK1 provides resource to examine whether the model predicts well the far field variability. The comparable model results were extracted from the grid closest to the location of GAK1, which were then interpolated to get the salinity and temperature at $20 \mathrm{~m}$ below the surface (Figure 3.1). Unfortunately, the bathymetry in the model was different from reality at this grid point; such that the water depth was only $45 \mathrm{~m}$ in the model compared to $264 \mathrm{~m}$ in the real world.

Because the integration started from the climatology, the initial condition was significantly different from observations at GAK1. However, after a short spin-up the modeled salinity and temperature matched the observations at GAK1 by April 2010 and captured the annual cycle in both years (Figure 3.1). In 2010 the rapid salinity drop, indicative of the arrival of the CR plume (see further discussion in Chapter 3.2), occurred in the beginning of July and the salinity rebounded in November. In 2011 , the sudden decrease in salinity occurred in August, which again rebounded in November. The WR case reproduced not only the mean salinity but also the large variability in summer better than the NR case, which indicates that the inclusion of river discharge as a point source even enhanced the model performance in far downstream. The summer variability shall be discussed further in Chapter 3.3. From December 2010 to early 

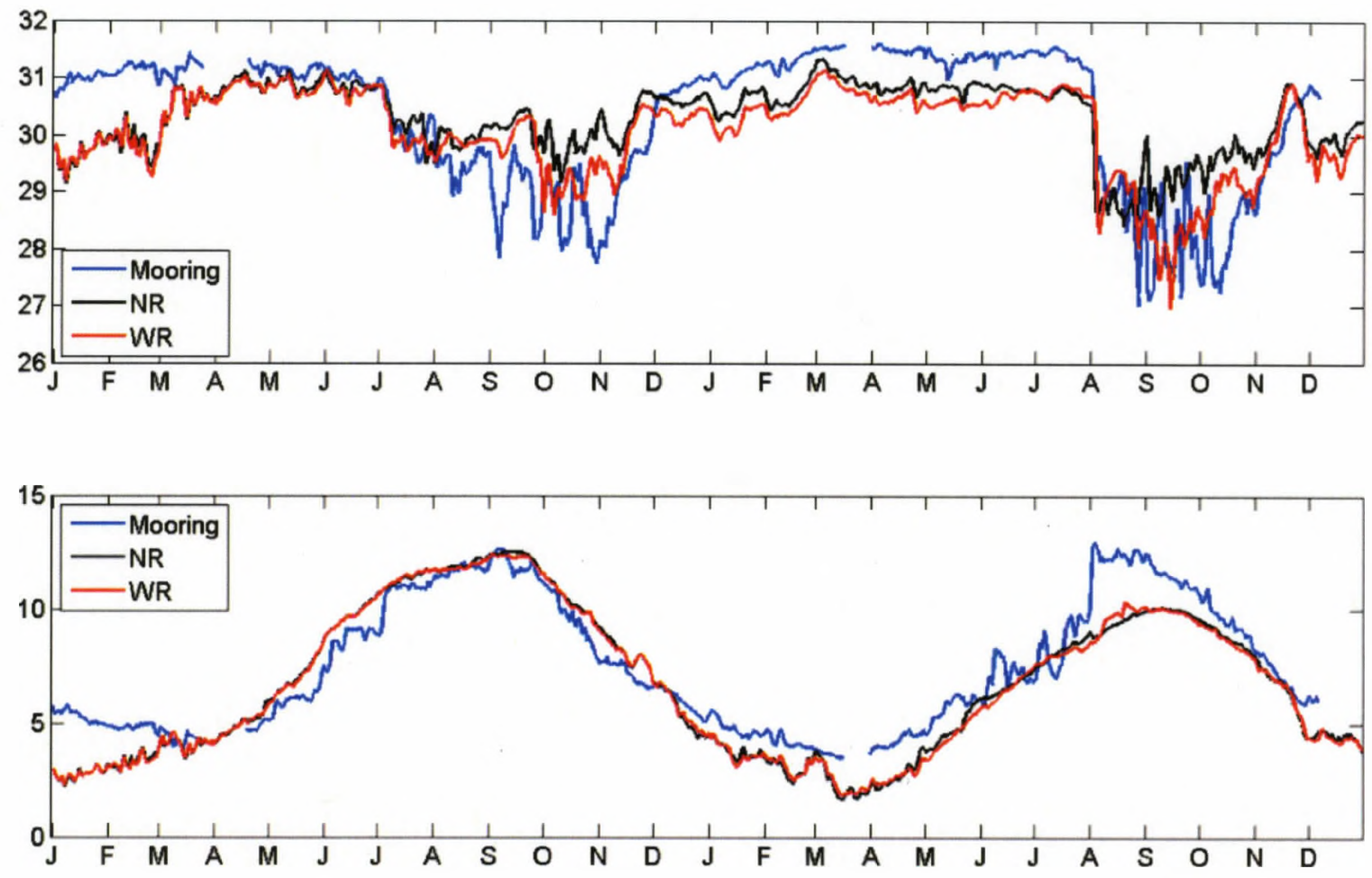

Figure 3.1 Comparisons of the salinity (unite: \%o) (upper panel) and temperature (unite: ${ }^{\circ} \mathrm{C}$ ) (lower panel) between the model (blue curve for the NR case and red curve for the WR case) and GAK1 mooring (black curve). 
August 2011 , the model was fresher than the mooring data by about $0.5 \%$, which might be partly related to the precipitation distribution scheme mentioned in chapter 2.1.

Royer (2005) analyzed three decades (1970-2000) of hydrographic data from GAK1 and found that the strongest freshening occurred from September to November when the standard deviation was also the greatest, which was attributed to the annual precipitation cycle. The comparison of NR and WR cases (Figure 3.1) demonstrated the impacts of the CR plume on the variability at GAK1 due to the gradual build-up of the plume in the summer and more rapid releasing in the fall (see sections 3.2 and 3.3 below). If similar behavior were to be expected for the countless streams along the coast of GoA, particularly the freshwater from PWS, this should add to the variability of the ACC and help to interpret the longtime hydrographic data series at GAK1.

The model appeared to reproduce the annual cycle of the temperature, better in 2010 but cooler in the first half 2011. The abrupt warming in early August 2011 coincided with the abrupt freshening in the salinity. Nevertheless, the model captured well the salinity change but missed the sudden change in temperature. Tracking the plume closely suggested the sudden decrease in salinity was associated with the plume being driven close to shore and forming strong downstream transport by the downwelling-favorable event in the beginning of August 2011, and the warming appears to relate to the associated warmer water in upstream of GAK1 but the model failed to reproduce such gradient. Such cooling in upstream should be attributed to the $\sim 20 \%$ less radiation from atmospheric forcing in southeastern GoA than in 2010. Differences 
between the two model cases were subtle, implying the CR discharge very little influence the temperature at this point.

\subsubsection{Cruise CTD casts}

The CTD casts during 27 to 29 July 2010 had an additional cast near shore ( 6 casts in total). The observed salinity (Figure 3.2a) suggests that the plume was more than $20 \mathrm{~m}$ deep near shore. The plume thickness decreased to $\sim 10 \mathrm{~m}$ at station 3 that was $\sim 15 \mathrm{~km}$ from the shore. The model reproduced well the salinity distribution at the first three stations. It further revealed that the $32 \%$ contour line deepened to $\sim 80 \mathrm{~m}$ depth albeit the feature was between CTD casts. However, the model salinity was slightly saltier in the surface than the observed further offshore. The modeled temperature (Figure 3.2b) agreed well with the observations near shore, but the model underestimated the warming in the surface layer and the intrusion of cooler water at depth further offshore. There was an onshore downward slope of isotherms at the base of the mixed layer between stations 5 and 4 (close to the month is the station 1), which was also present in the model. However, the temperature gradient at the base of the mixed layer was much weaker in the model. Notice that the bathymetry in the model was different from the real world, which could affect the flow field and, in turn, changed the plume geometry.

Comparisons between the model and all data from the eleven cruises are summarized using the Taylor diagram (Taylor, 2001), which shows the correlation coefficient, normalized standard deviation and the root mean square deviation (RMSD)

(Figure 3.3). All the correlation coefficients are significant $(p<0.001)$. The model results 
of 2010 generally achieved higher correlation coefficient and less RMSD, which might be related to the different forcing condition in two years. It appears to suggest that the model performance for the salinity was more consistent between the two years than that for the temperature. The Copper River discharge in the WR case introduced substantially more variability, especially in the salinity field, which resulted in higher correlation coefficient and less RMSD. The standard deviation of the model results was always less than that of the observation, which could be attributed to the limited grid resolution and impacts of other freshwater sources. However, the WR case appeared to be better because it reproduced about 80 to $90 \%$ of the observed standard deviation in salinity compared to less than $20 \%$ of the standard deviation in the NR case.

Furthermore, salinity in the WR case was also better correlated with the observations and had slightly smaller RMSD than the NR case. Although the improvement was small, the temperature in the WR case was also better simulated for the slightly higher normalized standard deviation and correlation but smaller RMSD.

The plume and its variability were well reproduced in the model especially for 2010. The temperature in the plume was also well simulated, but due to the uncertainties in the atmospheric forcing, the surface warming was underestimated. The mixing in the model might be too strong, leading to a deeper and narrower plume. Overall, the incorporation of the CR as a point discharge benefited the simulation, especially the salinity field not only near the river mouth but also far downstream. As such, only the WR case is further analyzed below to show the evolution of the CR plume. 

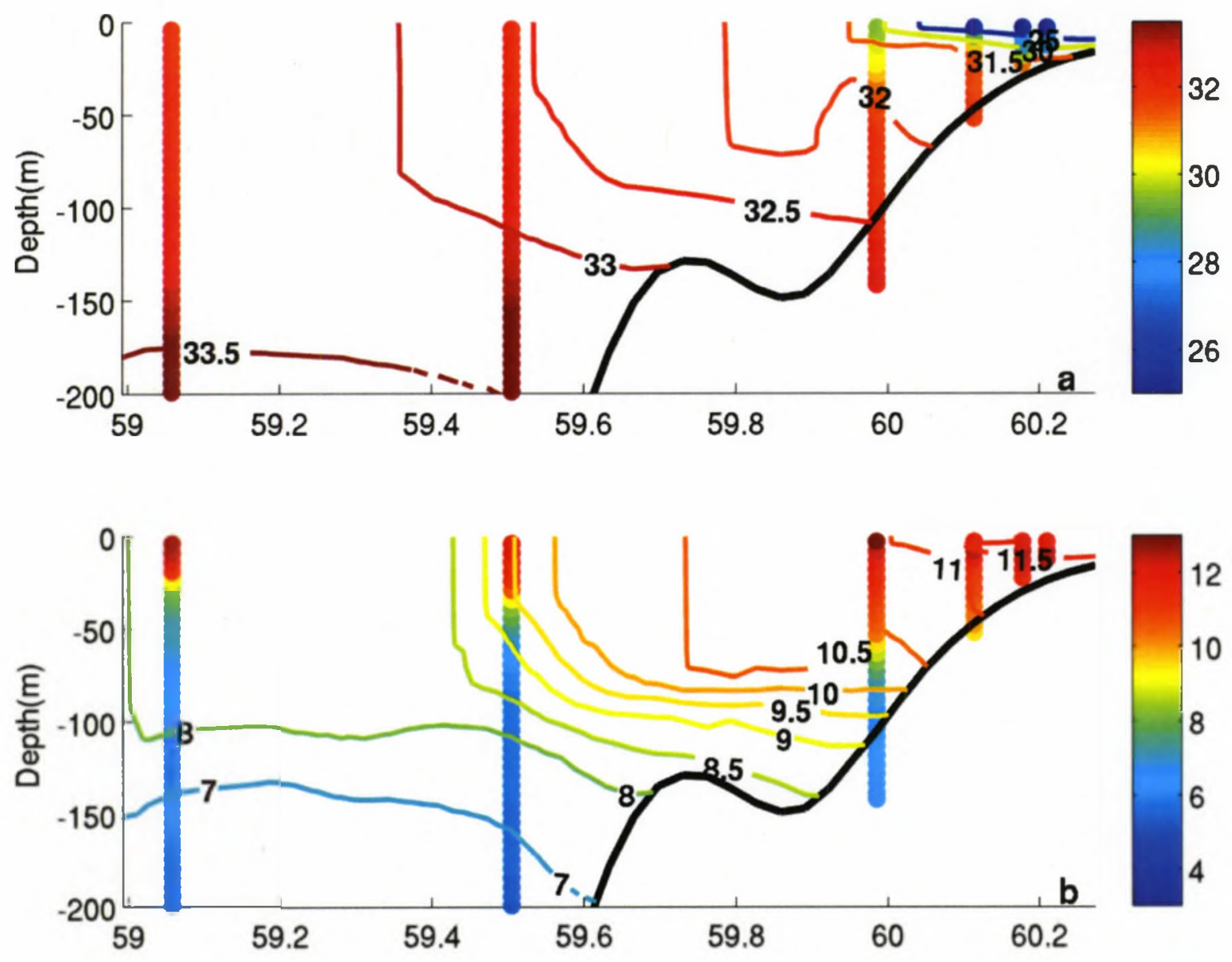

Figure 3.2 Comparisons between the model and CTD cruise No. 4. (during 27 - 29 July 2010 for a) the salinity $(\%)$ and $b$ ) the temperature $\left({ }^{\circ} \mathrm{C}\right)$. Colored dots indicate the observed data, and the model results are contoured. The black line represents the sea floor in the model. 


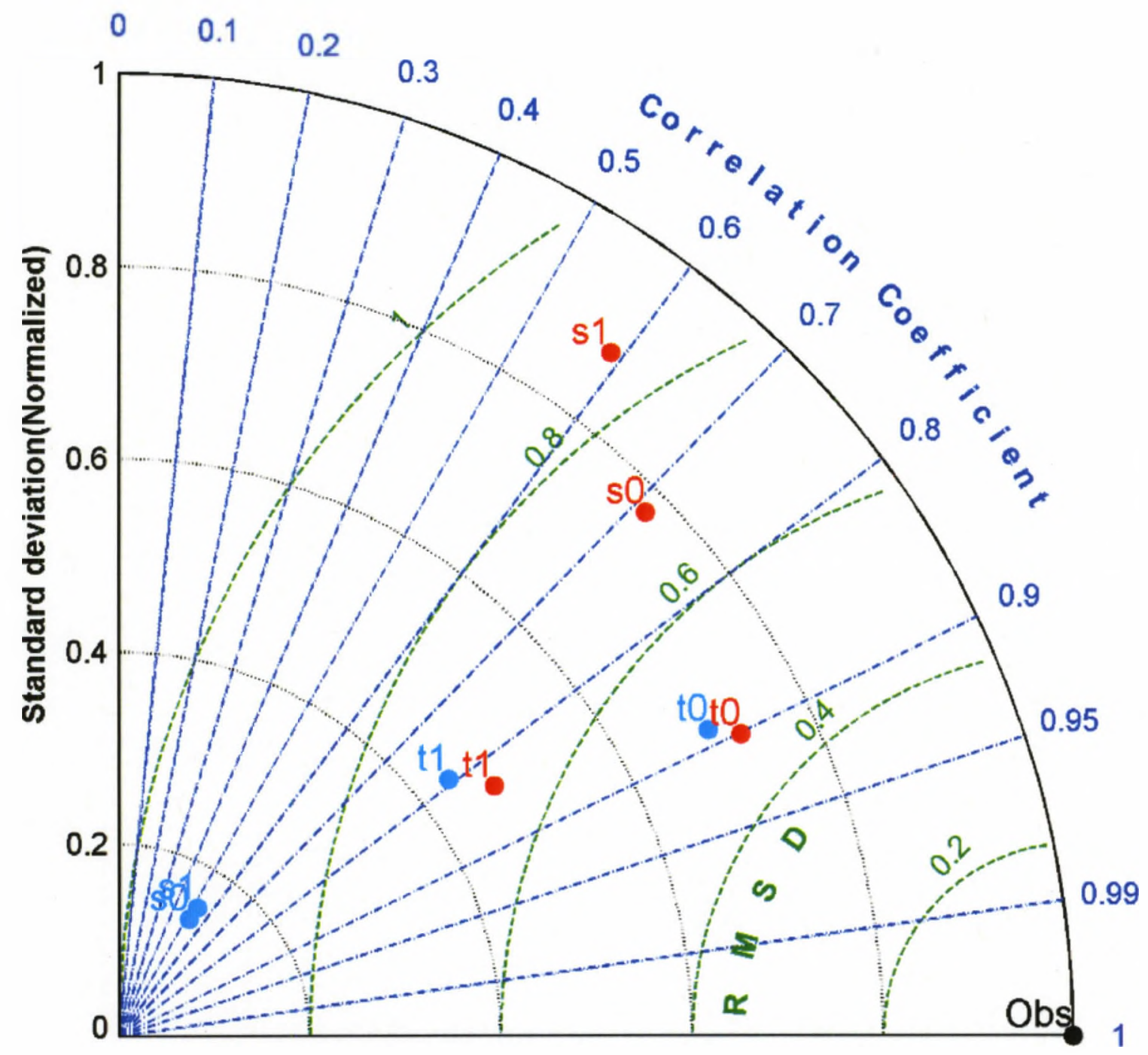

Figure 3.3 Taylor diagram to compare the model simulation with the CTD casts from the 11 cruises in 2010 and 2011 (see Table 3.1). The "Obs" indicates the perfect match with the observations. The RMSD is represented by the position of each indicator and the distance from the indicators to the "Obs" point. The standard deviation of the model is normalized to the observation. $(\mathrm{s} 0, \mathrm{t} 0) /(\mathrm{s} 1, \mathrm{t} 1)$ correspond to the (salinity, temperature) in 2010/2011. The cyan/red dots indicate the model results in NR/WR case. 


\subsection{The CR plume evolution}

The CR plume driven by the seasonal forcing described in the introduction exhibited prominent seasonality. From the end of October to the beginning of May the following year, the plume was restricted in the estuary due to the intense downwellingfavorable wind $\left(0.1 \mathrm{~N} \mathrm{~m}^{-2}\right.$ on average) as well as low river discharge $\left(<300 \mathrm{~m}^{3} \mathrm{~s}^{-1}\right)$. As the river discharge gradually increased beginning in April $\left(200-600 \mathrm{~m}^{3} \mathrm{~s}^{-1}\right)$ and the downwelling-favorable wind (blue bars in Figure 3.4c) weakened beginning in May, the volume and passive tracer content of the plume increased significantly (Figure 3.4a and b) and a bulge of brackish water established in May. Accompanying the increasing discharge, the plume volume gradually increased to its maximum at the end of August in 2010 , which lagged the maximum discharge by about a month. By mixing with the ambient water, the maximum plume volume exceeded 2 times of the total freshwater discharge volume of the year. In contrast, the storm at the beginning of August 2011 shut off the accumulation of the plume, leaving the volume peak in 2011 much less than its counterpart in 2010 . When the plume volume reached its maximum, the mean concentration of the passive tracer in the plume was $\sim 10 \mathrm{mmol} \mathrm{m}^{-3}$ at that time. Soon after the plume volume reached its maximum, it collapsed in less than a month to the equivalent size in May. After the end of October, the plume retracted back to the estuary again. 

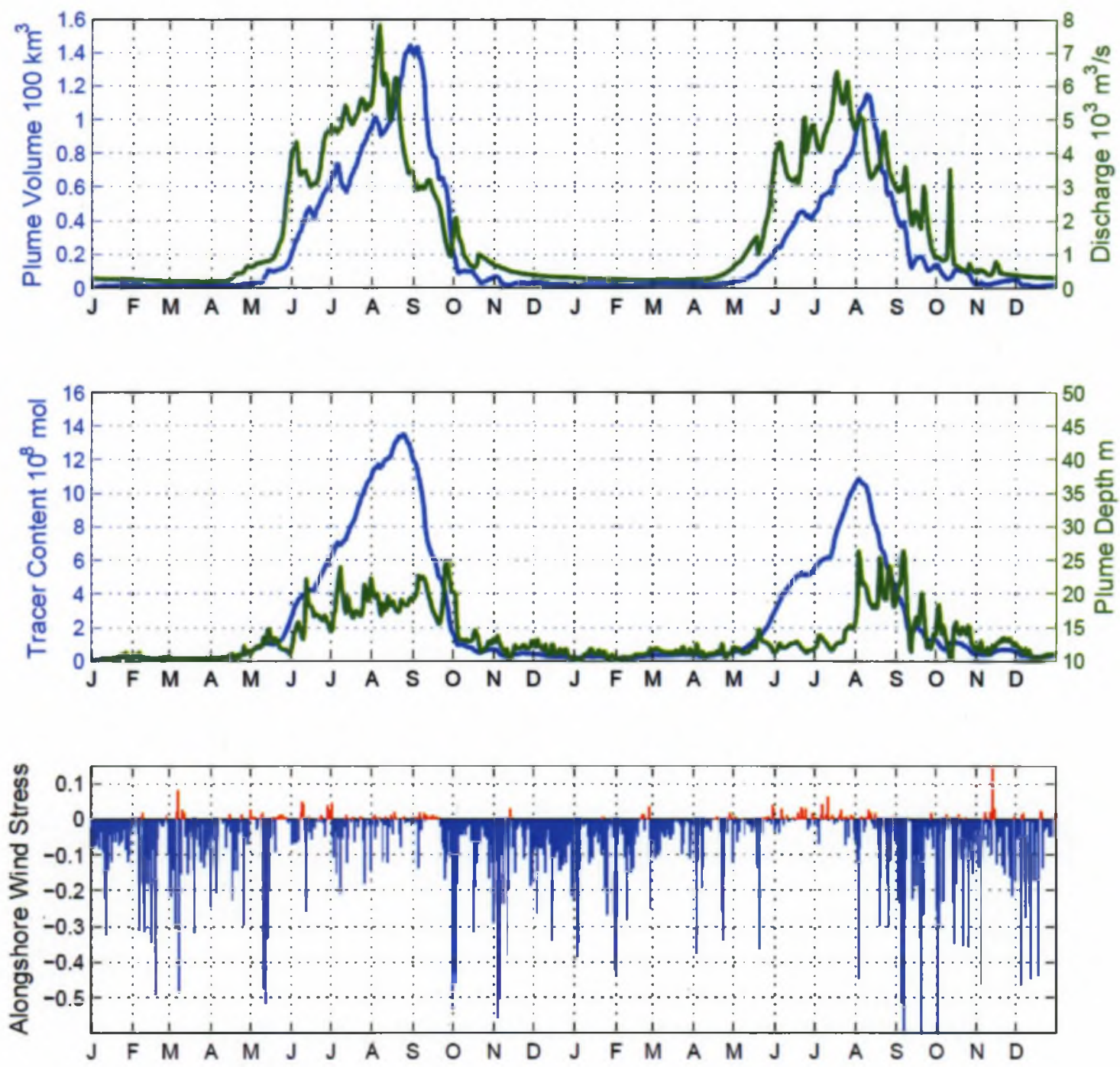

Figure 3.4 Time series of the CR discharge and the plume volume (a), the passive tracer content in the plume and mean depth of the plume (b), and the alongshore wind stress $\left(\mathrm{N} \mathrm{m}^{-2}\right)(\mathrm{c})$ in $2010-2011$. 
The plume depth evolved differently in the two years, which appeared to result from the different wind conditions. In summer 2010, the abrupt increase of depth coincided with episodic downwelling-favorable events (Figure 3.4b and c). In 2011, as weak and more persistent upwelling-favorable winds tend to thin the plume in the first half of summer, the plume depth stayed at $\sim 10 \mathrm{~m}$ until the arrival of the downwellingfavorable wind in the end of July. The strong downwelling-favorable event in the beginning of August (Figure 3.4c) pushed the plume onshore, and the volume started to decrease as the frequent storms kept disturbing the depth of the plume and the total passive tracer content lost quickly in September (Figure 3.4a and b).

From the similarity and difference of the annual cycle in both years, one can separate the "summer" (June to September) into "early summer" (June to July) and "late summer" (August to September). Then, it can be summarized as, (1) the discharge increase in early summer and decrease in late summer, and (2) the upwelling-favorable wind dominant early summer 2011 while the strong downwelling-favorable wind dominant late summer 2011. With this definition, the statistics of plume occurrence, depth and stratification in those seasons offer an overall view of the plume residence time, propagation and mixing with the ambient water with respect to certain condition.

From June to July, the river discharge increased to its peak, and the plume volume increased continuously (Figure 3.4a). However, the plume evolution in this period was distinctly different between 2010 and 2011 as seen from the plume occurrence (Figure 3.5a, b). In the early summer, the strong downwelling-favorable wind happened intermittently from June to July in 2010 (see Figure 3.4c). The plume 
established a stable (frequency $>0.8$ ) bulge near the river mouth and a westward extension off Hinchinbrook Island (Figure 3.5a). The westward alongshore extension reached the tail of Montague Island, but the offshore extent was suppressed to less than $60 \mathrm{Km}$ from the coast. In contrast, the alongshore wind was much weaker and included frequent upwelling-favorable wind events during the same period of 2011 (see Figure 3.4c). In 2011, the plume was separated from the shore, and the plume was shallower (Figure 3.4b) and closer to the shelf break than during the same period in 2010. Consequently the plume was more susceptible to the mesoscale eddies embedded in the Alaskan Stream, leading to early offshore transport (see Chapter 3.3). In late summer 2010 , the continuingly relaxed wind allowed the plume to grow even though the discharge started to decrease. The plume expanded both crossshore and alongshore and its volume reached its maximum at the end of August. Particularly, its offshore boundary advanced close to the $200 \mathrm{~m}$ isobath (Figure $3.5 \mathrm{c}$ ). While in the late summer of 2011, the early onset of the downwelling-favorable wind started in the beginning of August and the river discharge reduced significantly (Figure 3.4a). The plume was pushed against the shore with its center confined to inside the $50 \mathrm{~m}$ isobath (Figure 3.5d). The enhanced downstream extension of the plume suggested intense transport of brackish water to downstream, which was consistent with the large salinity variability at the GAK1 mooring after August (see Figure 3.1). Although the discharge spiked again several times (reaching 3500 to $4800 \mathrm{~m}^{3} \mathrm{~s}^{-1}$ ), the plume was mixed deeper corresponding to the stormy condition but the plume volume never recovered (Figure 3.4). The depth of the plume (white contours) indicated that the plume was generally 


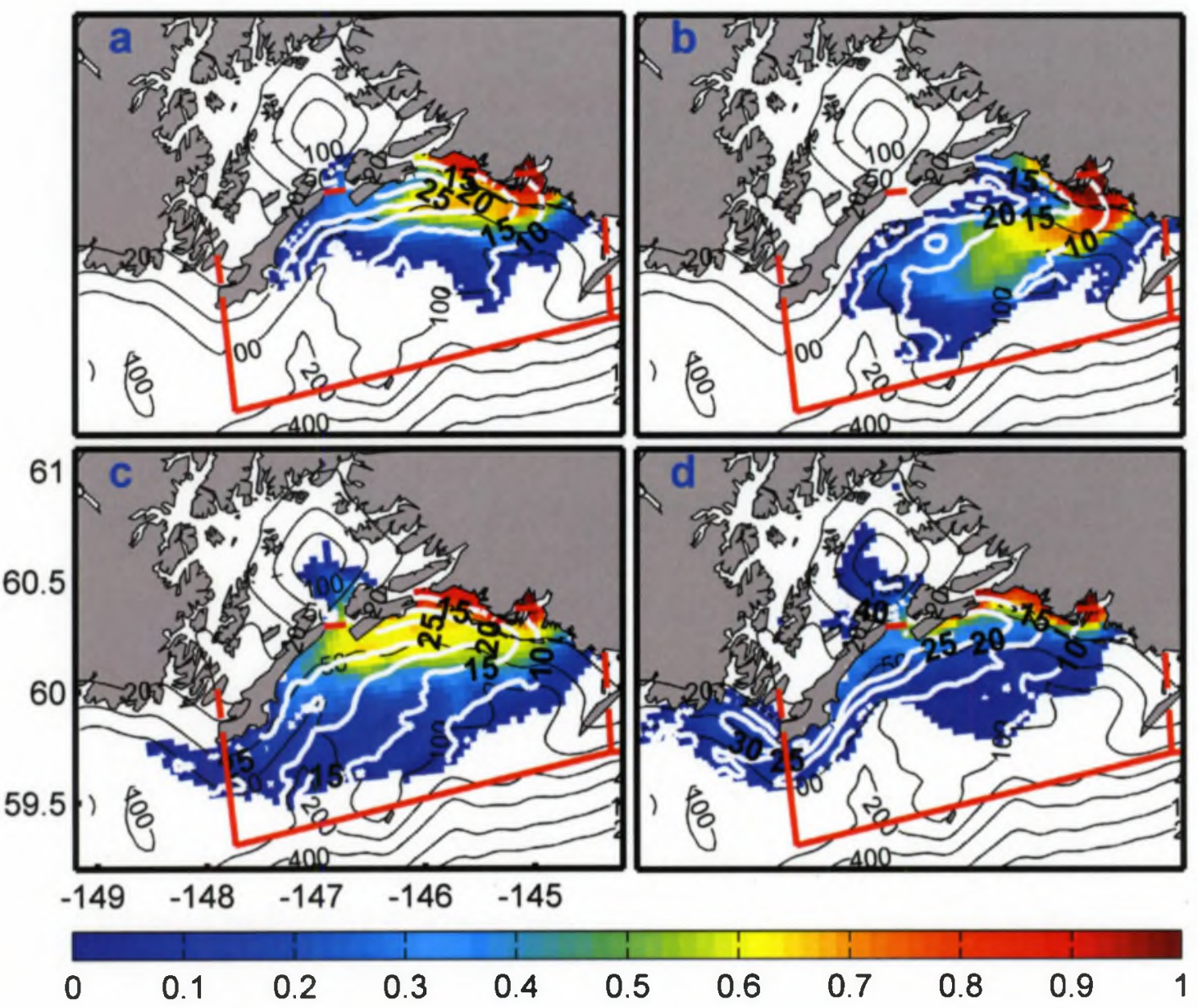

Figure 3.5 Plume occurrence frequency (color) and the associated plume depth (white contour lines: $10,15,20,25,30,35 \mathrm{~m}$ ) in (a) June - July of 2010; (b) June - July of 2011; (c) August - September of 2010; and (d) August - September of 2011. 


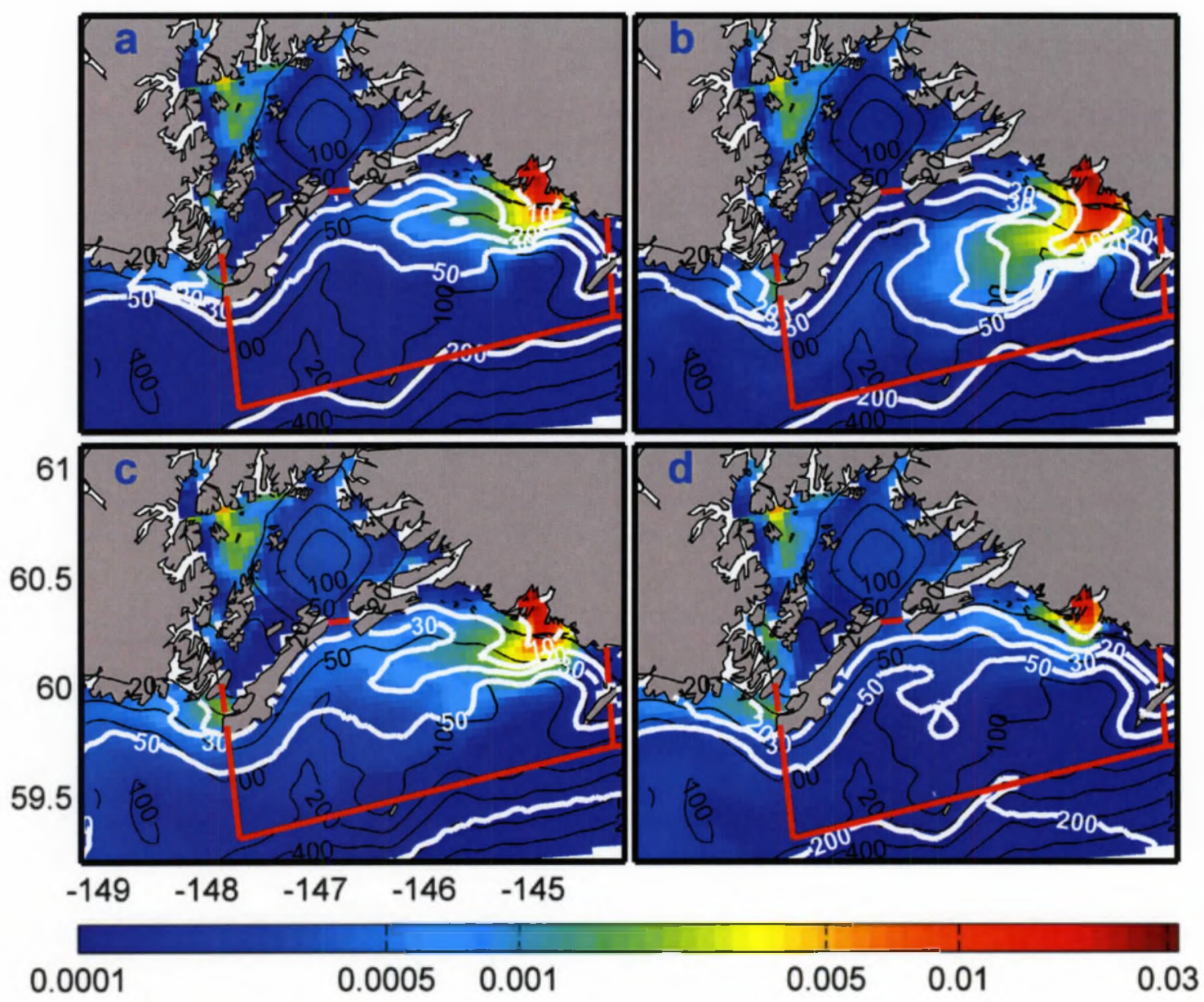

Figure 3.6 Similar to Figure 3.5 but for the maximum $\mathrm{N}^{2}$ (color) and its associated depth (white contour lines: 10, 20, 30, 50, 200m). 
deepened toward downstream, and the gradient of plume depth was larger in downwelling-favorable wind dominant periods (early summer 2010 and late summer 2011).

One can notice that the plume is vulnerable to strong downwelling-favorable wind that drains the plume efficiently and forms intense downstream alongshore transport. During the relaxed wind condition, the plume is capable to grow if the discharge is high enough (see chapter 3.4). In order to evaluate the relative importance of the discharge in plume evolution, an idealized model experiment similar to Kourafalou et al. (1996) and Fong and Geyer (2002) can provide more knowledge on the balance between the input via the discharge and the removal due to advection and mixing in this area.

To illustrate the stratification, shown in Figure 3.6 is the mean Brunt-Vaisala frequency, $\mathrm{N}^{2}$, for the specified periods calculated using the maximum $\delta \rho / \delta H$ (between the surface and a given depth) in each day. Generally, $N^{2}$ decreased significantly away from the river mouth, and the $\mathrm{N}^{2}$ value was more than 2 orders higher near the river mouth than outside of the plume occurring region (Figure 3.6). The depth associated with the maximum stratification (white contours) was deeper than the plume depth (Figure 3.5), which indicated that the plume definition was more strict than $\delta \rho / \delta H$ here. Between Kayak Island and Montague Island, the stratification was dominated by the CR discharge, as the $\mathrm{N}^{2}$ value was consistent with the plume occurrence shown in Figure 3.5 . One can also notice that the freshwater source in PWS resulted in strong stratification in 
PWS but the area of elevated stratification between the Montague Island and GAK1 could be attributed to freshwaters from both the CR and PWS especially in August and September as suggested by the CR plume occurrence shown in Figure 3.5. This also points to the need for introducing the passive tracer to decipher the impact from the $C R$ discharge solely.

\subsection{CR plume and the along- and cross-shore transport in NGoA}

The alongshore and offshore transport of riverine input plays an important role in the coastal ecosystem. It is of interests to understand how physical processes regulate the transports and this can be investigated using inert tracers in numerical ocean models because this approach eliminates all biogeochemical processes related to other properties. Eight transects (see Figure 2.1) were selected to examine the transport of the passive tracer originated from the CR. The offshore boundaries (OU and OP) were roughly aligned with the shelf break (the $200 \mathrm{~m}$ isobaths). The annual transport through each selected transects is converted to the percentage of total input from the CR in each

year (Figure 3.7). The upstream transport across transect U1 was negligible in both years. One third of the CR input entered PWS via S1, and half of which came back to the shelf via S2 in 2010 but two thirds of which in 2011. This indicated that PWS hadn't been saturated with the passive tracer yet even after two years. About two thirds of the passive tracer from the river were transported directly downstream through the P2 transect. Including the outflow from PWS via S2, there was $78 \%$ and $90 \%$ percent of the passive tracer input exported to the downstream region in 2010 and 2011, respectively. 
Despite the fact that it was small, a more significant change from 2010 to 2011 was the offshore transport, with the 2010 value being about $300 \%$ of its counterpart in 2011 . As the advection was much stronger in the shelf, the residence time on the shelf $(\tau=V / q, V$ is the volume corresponding to the area $P$ or $S$ in Figure 2.1, and $q$ is the total volume transport into the area through associated transects) was about 10 days. There was no considerable passive tracer residual on the shelf at the end of each year. It is worth to notice that, ideally, the sum up of fluxes through $\mathrm{P} 2, \mathrm{P} 1, \mathrm{~S} 2, \mathrm{OP}$ and residual in area $\mathrm{P}$ should be 100 percent. However, the fluxes add up to more than 100 percent. Such $5 \%$ error should partly introduced by the flux calculation, which is the product of daily averaged speed and concentration.

The plume evolution was distinct due to the forcing variability from one year to another (see Chapter 3.2 above), which led to the differences in transport between the two years (Figure 3.8a). In 2010, the downstream transport (P2) began in June. It was relatively stable during much of July and August, followed by two peaks in September and then a rapid shut off in early October. In contrast, despite of the similar build-up in late June and much of July the downstream transport in 2011 peaked in the beginning of August. A secondary peak occurred in late August followed by a gradual decrease in September. Similarly, the transport into PWS (S1) had smaller values but lasted longer in 2010 compared to in 2011, but the peaks in August and September 2011 were much higher. 


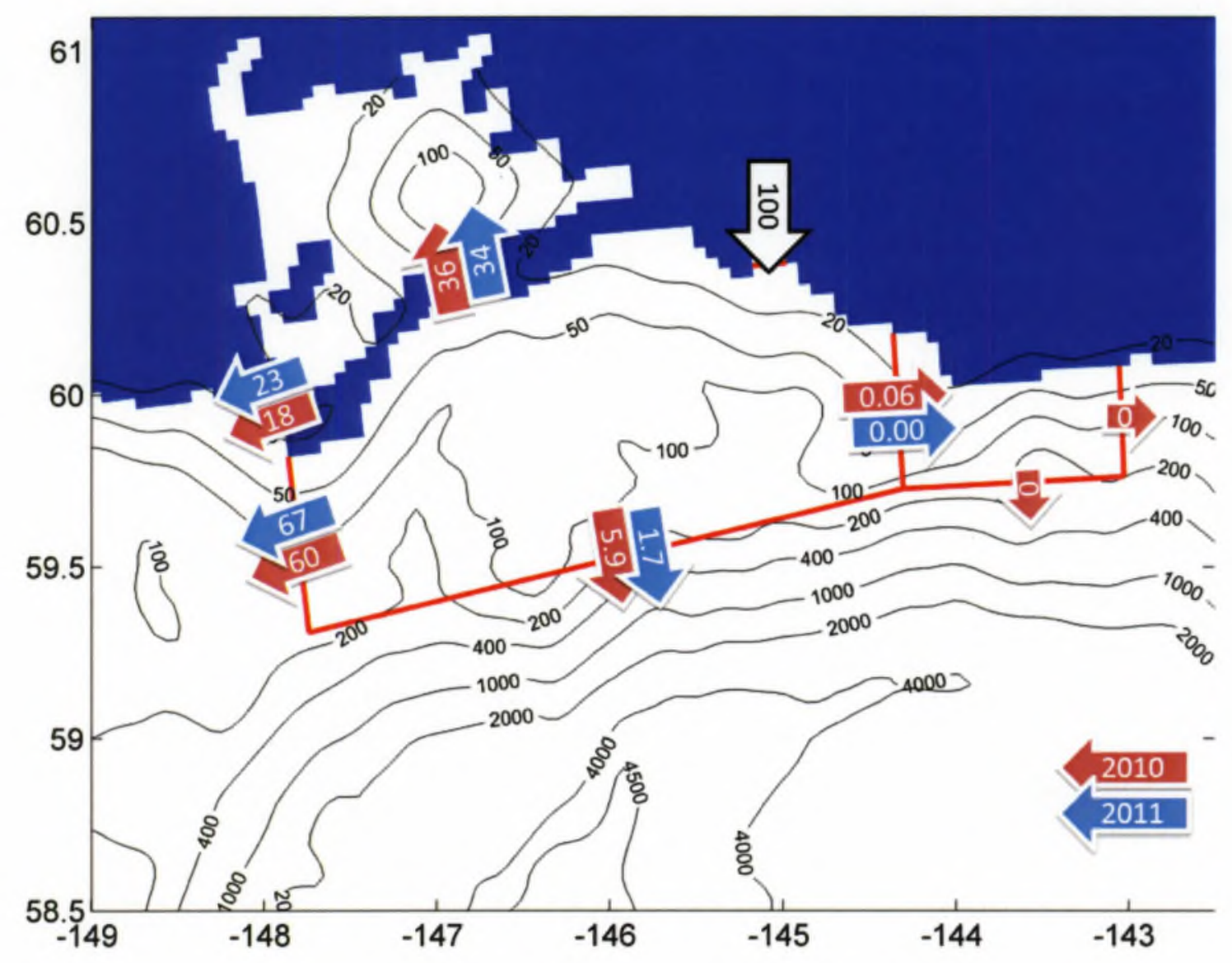

Figure 3.7 Yearly integrated fluxes of the passive tracer at selected transects normalized to the river input in $2010-2011$, respectively. 

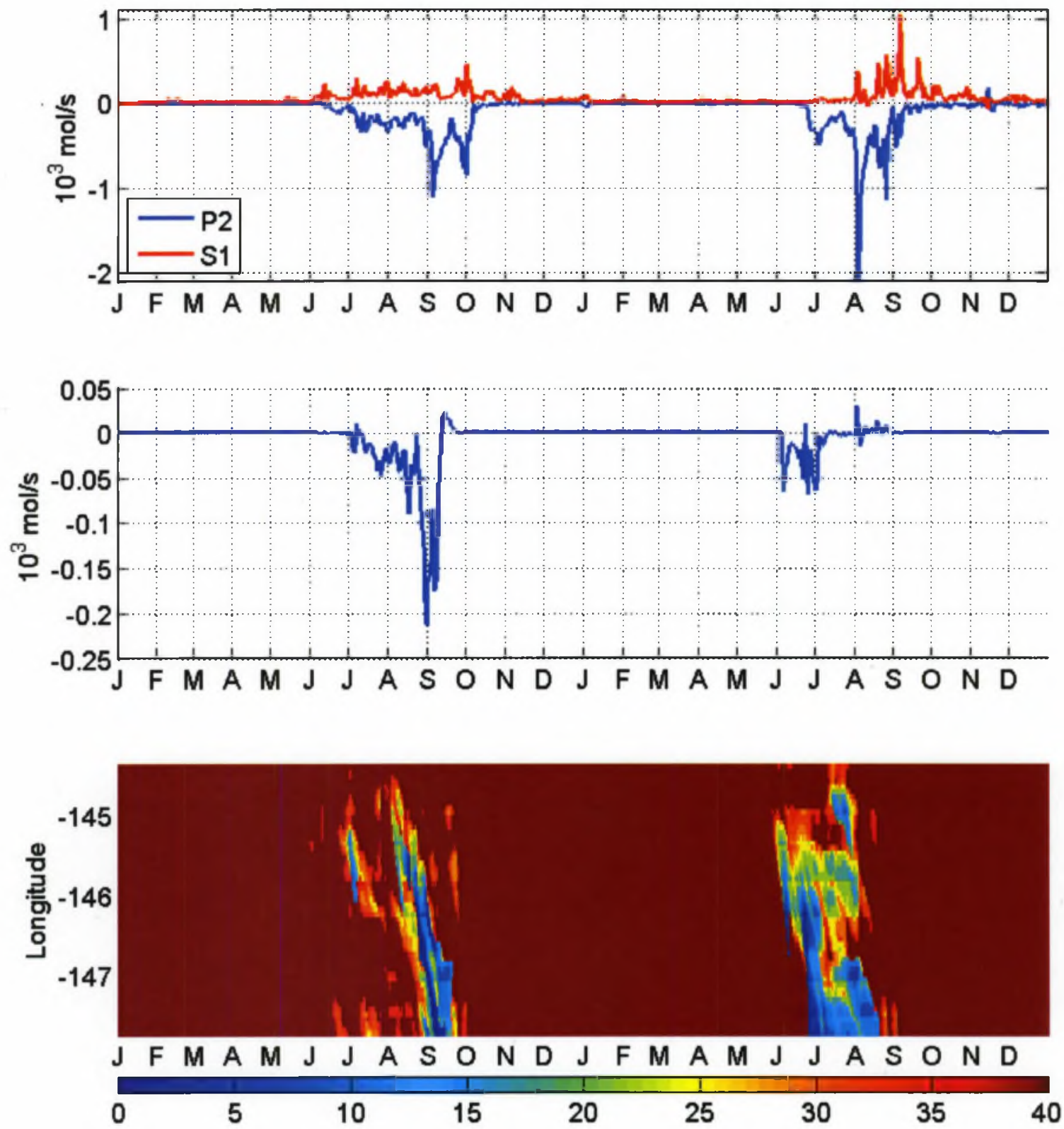

Figure 3.8 (a) Time series of the downstream transport at P2 (blue line) and the transport into PWS at S1 (red line); (b) time series of the offshore transport at OP; (c) the distance $(\mathrm{km})$ from the $1 \mathrm{mmol} \mathrm{m}^{-3}$ passive tracer concentration contour line to the offshore transect OP. 
Much of the difference between the two years in the downstream transport and the transport into PWS can be explained by the timing of discharge and variability of the wind. Downwelling-favorable wind promotes both the downstream transport and the transport into PWS (Figure 3.9). However, the high discharge period in summer usually coincides with the relaxation of downstream favorable wind in the NGoA. Hence one would expect a typical summer like 2010 with moderate transports both downstream and into PWS in response to mild wind events until the arrival of the strong easterly wind in the fall while the discharge has reduced. In contrast, the downwelling-favorable wind events occurred much earlier in 2011 starting with an unusual storm in the beginning of August while the discharge was still high. An intense coastal current emerged very close to shore (Figure 3.9b). Correspondingly, the alongshore transport peaked (Figure 3.8a) to impact heavily on downstream locations such as GAK1 (see Figure 3.1). On the other hand, because the downstream transport was so high $(\sim 2000$ $\mathrm{mol} \mathrm{s}^{-1}$ ) in early August, the plume lost much of its content (Figure 3.8b) and shrunk dramatically by September (see Figure 3.4a) despite of the similar river discharge. Subsequently, the majority of the flux turned to S1 rather than P2, which was related to the shrunken plume and its downstream extent was not able to reach P2 (Figure 3.9 a and $c$.

A different cause was responsible for the downstream transport event in the beginning of September 2010. It was accompanied by a dramatic increase in the offshore transport at transect OP from late August to early September (Figure 3.8b), which was generated by plume frontal instability (Figure $3.9 \mathrm{~d}$, e and f) due to the buoyancy built up leading to 
this point. The plume fringe started to hit the transect OP on 21 August. A great amount of buoyancy that accumulated in the shelf from the peak discharge in the first half of August and the simultaneous relaxation of wind favored the offshore expansion of the plume. A blob of the plume water broke off, which was entrained in the AS and pulled offshore as seen in Figure 3.9e. Due to the high concentration in this blob the first peak in the offshore transport took place on 31 August, when the first branch of the offshore flow (the leading edge of the blob) moved westward and a second branch of offshore flow was induced by the AS near the trailing edge of the blob. The blob and the frontal features continued to move westward (Figure 3.8c) and pushed slightly onshore by the weak and abrupt downwelling-favorable event in the beginning of September and the offshore transport was reduced temporarily while the alongshore transport increased. This downwelling-favorable wind event lasted only two days followed by about a week of weak upwelling (see Figure 3.4c), which allowed the frontal features stretched back to the offshore transect OP (Figure 3.9f) and the offshore transport reached its secondary peak on 6 September. After that, offshore transport decreased significantly due to the draining of the buoyancy by the heightened alongshore transport. In contrast, the plume never reached such a status of full growth in 2011 because the early onset of downwelling-favorable wind drained the buoyancy in the downstream direction and limited the plume growth in the offshore direction. Hence the offshore transport was quickly shut off. 


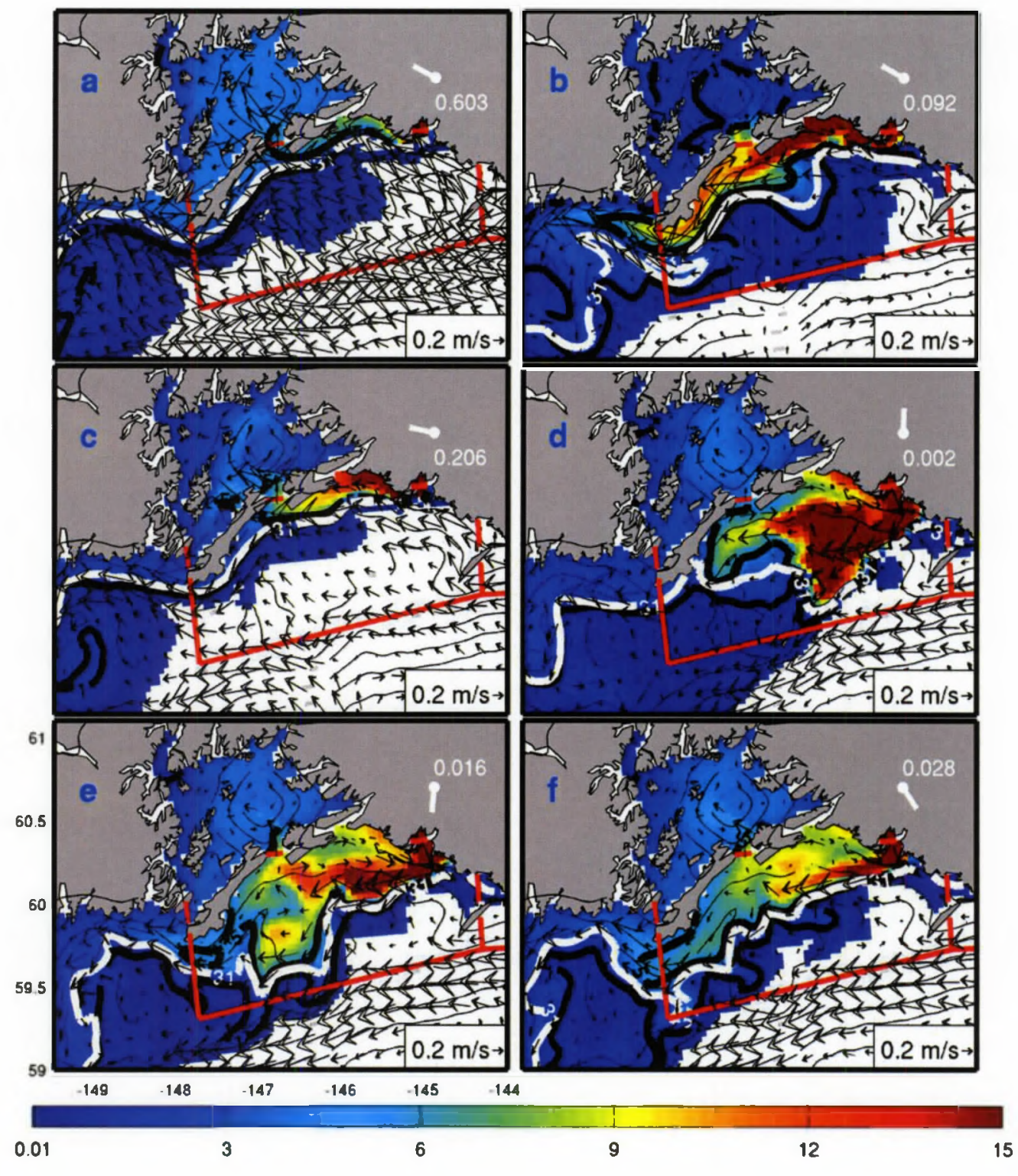

Figure 3.9 Snapshots of the passive tracer distribution in the NGoA on 1 October 2010

(a), 4 August 2011 (b), 4 September 2011 (c), 21 August 2010 (d), 31 August 2010 (e) and

6 September 2010 (f). The color indicates the concentration of the passive tracer (only the concentration higher than $0.01 \mathrm{mmol} \mathrm{m}^{-3}$ is colored), and the contoured lines represent the $31 \%$ salinity contour (white) and the 1 and $5 \mathrm{mmol} \mathrm{m}^{-3}$ passive tracer contours (black). White arrows (start from dots) in the upper-right corner indicate the daily mean wind stress in $\mathrm{N} \mathrm{m}^{-2}$. 
During the plume decaying period, (September to October in 2010 and August to October in 2011) (Figure 3.8a) the draining rate (R) of the passive tracer through $P 2(R=$ $\mathrm{F} / \mathrm{C}, \mathrm{F}$ is the flux and $\mathrm{C}$ is the total content of passive tracer in the plume) were significantly correlated to the wind stress (correlation coefficient $=0.39, p<0.001$ ) . Moreover, the draining rate at S1 was even better correlated to the wind stress (correlation coefficient $=0.48, p<0.001$ ). This indicated the wind is one of primary driving factors for the downstream transport and the transport into PWS such that the stronger the downwelling-favorable wind stress the stronger the fluxes through P2 and S1. In contrast, the flux through OP didn't correlated with the wind stress (correlation coefficient $=0.11, p=0.19$ ), implying factors (such as the frontal instability and offshore current entrainment seen in Figure 11d-f) other than the wind played a more important role in driving the seaward flux.

In the GoA, large-scale, cross-shore exchange has been explained by estuarinelike circulation driven by the large freshwater input along the coastline (Royer, 1975). The cross-shore exchange induced by eddies was also observed in NGoA (Stabeno et al. 2004). Eddies typically form in the NGoA during fall and winter, and propagate southwestward within a $200 \mathrm{~km}$ wide corridor along and above the continental slope (Okkonen 2003, Henson and Thomas 2008). In our study, the entrainment induced by mesoscale eddies was documented during July 2010 in WR Case (no show in Figures), which mismatched the offshore expansion of the main part of the plume and didn't generate intense offshore transport. On the other hand, a huge meandering/eddy like mesoscale feature was captured during July and August 2011 (the northern fringe can 
be seen in Figure 3.9b). This feature redirected the AS, leaving sluggish flow on the shelf break and reducing the velocity shear, which contributed partly to the early shut off of offshore transport in July (Figure 3.8b). The interaction between river plume and offshore current system was also observed in the Mississippi River plume (Schiller 2011). The loop current and its associated eddies exert significant impacts on the distribution and pathway of the Mississippi River plume. We suspect that eddies in NGoA could significantly affect the transport of the CR discharge if they impinged onto the shelf break when the plume is near.

\subsection{The effect of the CR discharge on transport variability in X2 case}

In order to understand the effect of anticipated discharge increase associated with climate change scenarios, a double discharge case $(X 2)$ is conducted and compared to the normal discharge case (WR). The overall transport pattern of riverine input was similar (Figure 3.10): almost zero upstream, 60\% downstream, $\sim 30 \%$ into PWS, and the rest offshore. Moreover, about $40 \%$ of the passive tracer that entered PWS remained in both cases. Compared to the WR case, the transport downstream and into PWS reduced by 3 and $17 \%$, respectively, but the offshore transport was significantly enhanced in the $\mathrm{X} 2$ case by more than $300 \%$.

The plume evolved differently in two cases (Figure 3.11a). The maximum volume of the plume was 3 and 2 times of its counterpart in the WR case in 2010 and 2011, respectively. In 2010, the plume continued growing well into September, followed by a quick collapse in October in a manner similar to that in the WR case. However, in 2011 
although the plume decayed in response to the strong downwelling-favorable event at the beginning of August 2011, the volume rebounded afterwards and didn't show any substantial decrease until the second half of October, which was in stark contrast to the WR case (see Figure 3.4a). This was related to the heightened transport into PWS driven by the downwelling-favorable wind events in 2011 (Figure 3.11b). Consequently, the mean concentration of the passive tracer was greater than $5 \mathrm{mmol} \mathrm{m}^{-3}$ in PWS even after the plume diminished on the shelf (not shown), due to the longer residence time in PWS compared to in the shelf, the plume was sustained well into October.

The most noticeable differences in the flux at P2 occurred in July and early September. In the $\mathrm{X} 2$ case, a significant peak in the downstream transport took place in early July (Figure 3.11b and 3.12a) due to a prolonged downwelling-favorable wind despite its moderate strength, which exceeded four times the value of its counterpart in the WR case (Figure 3.8a). Similarly, another peak at the end of July also exceeded three times the value of its counterpart in the WR case. In contrast, the early September peak disappeared in the $\mathrm{X} 2$ case. Because the offshore transport associated with the frontal instability and entrainment of the AS was greatly enhanced closer to the eastern end and mid-section of transect OP, proportionally less reached the downstream transect P2 (Figure $3.12 \mathrm{~b}$ and c) until the downstream favorable wind picked up in late September, and only then the flux at P2 reached its maximum. The peak flux was $\sim 3000 \mathrm{~mol} \mathrm{~s}^{-1}$, which drained the plume content greatly (see the volume in Figure 3.11a and passive tracer content in Figure 3.4b) so that the next wind event in the beginning of October 


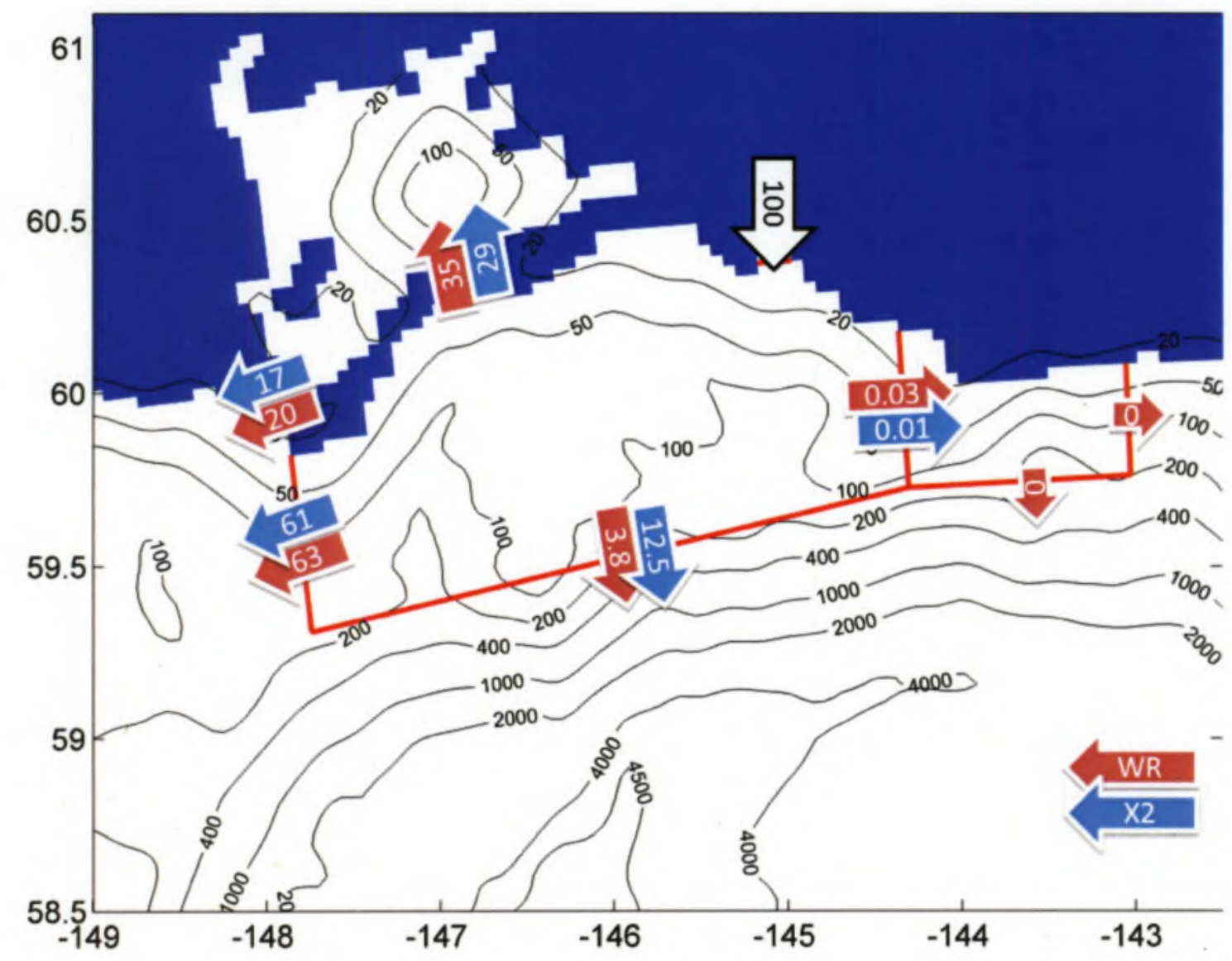

Figure 3.10 Comparison of along- and cross-shore transports between the $\mathrm{X} 2$ case (blue arrows) and the WR case (red arrows). The transports are integrated over 2010 and 2011 and normalized by the riverine input over the two years. 

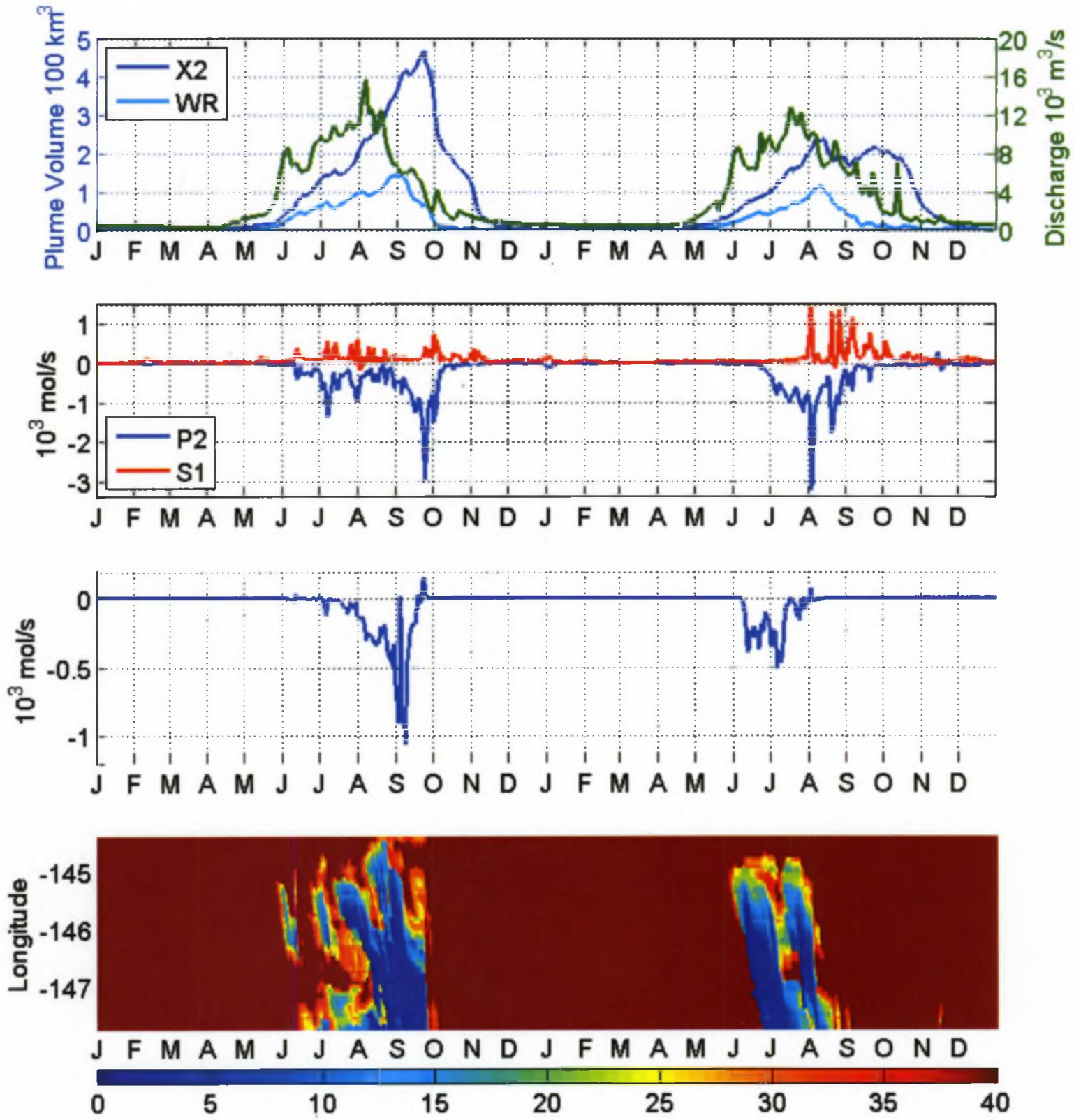

Figure 3.11 Time series for 2010 and 2011 in the $X 2$ case: (a) the river discharge and the plume volume; (b) the downstream transport at P2 (blue line) and the transport into PWS at S1 (red line); (c) the offshore transport at OP; and (d) the distance (km) from the $1 \mathrm{mmol} \mathrm{m}{ }^{-3}$ passive tracer concentration contour line to the offshore transect OP. 


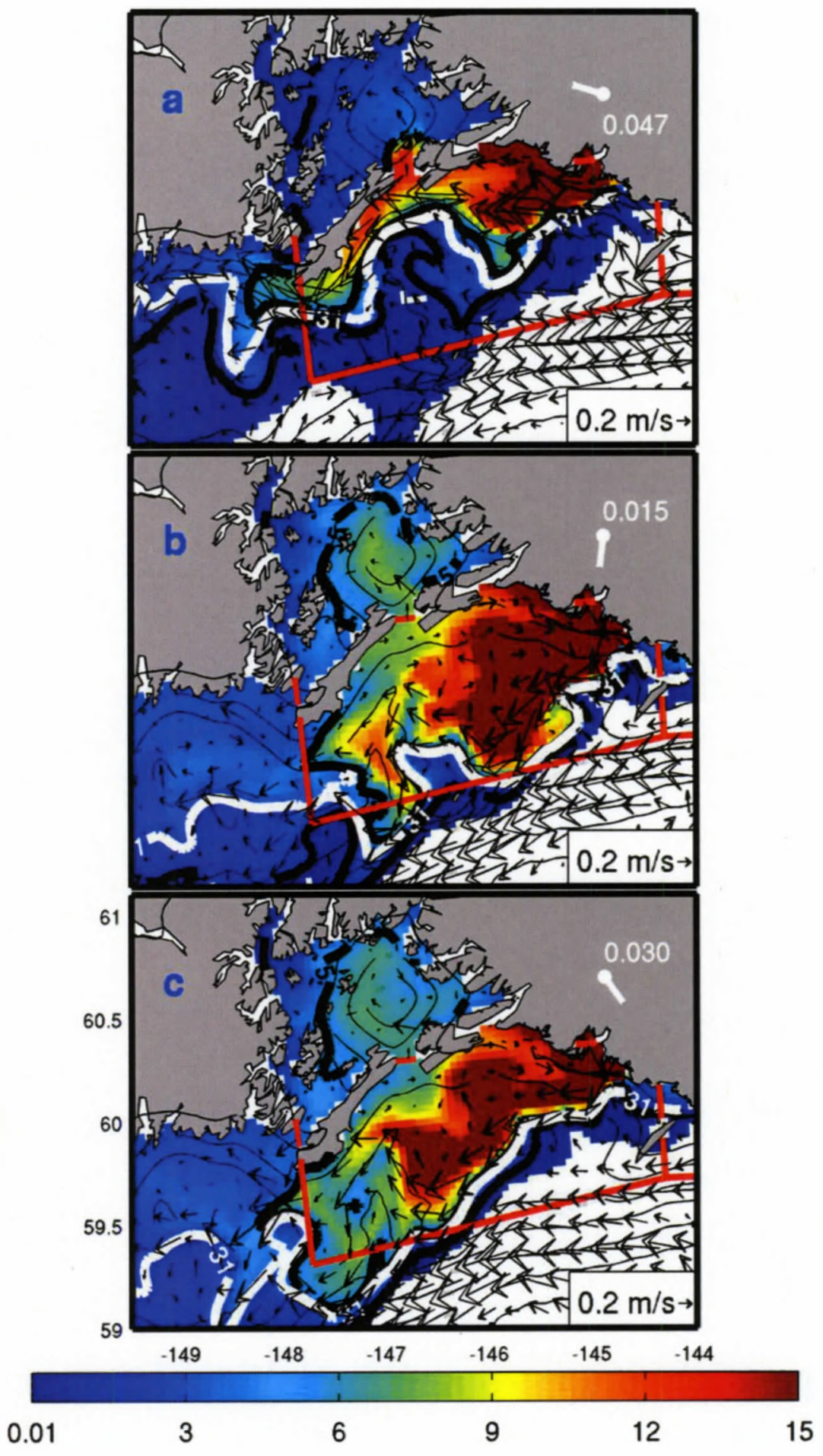

Figure 3.12 Snapshots of the passive tracer distribution. Similar to Figure 3.9 but for (a)

7 July 2010, (b) 31 August 2010, and (c) 6 September 2010 in the X2 case. 
produced a substantially smaller peak. The pattern of downstream transport in 2011 was qualitatively similar between the two cases, so was the transport into PWS.

The plume was markedly larger in X2 case and thus closer to transect OP for much more time (Figure 3.11d), which offered more opportunities for offshore transport (Figure 3.11c). As expected, the magnitude was dramatically enhanced by $437 \%$ and $1037 \%$ in 2010 and 2011 respectively. However, the timing was almost identical, especially the starting point. The ending point in 2011 trailed a bit longer as the first signal of plume front exited to the west in mid-July. Additional smaller peaks in the second half of July were related to the peak discharge and larger size of the plume.

To summarize, upstream (eastward) transport of riverine materials is negligibly small; about one third goes into PWS and close to $60 \%$ of which exits PWS from the southwest; the southwestward transport on the shelf is about $60 \%$ off the southern tip of the Montague Island; and the rest few percent is transported across the shelf break to the open gulf. The downstream transport and the transport into PWS are highly regulated by the discharge and downwelling-favorable wind, while the offshore transport is related to the accumulation of plume water in the shelf. Because the wind is often weak during the peak discharge period in summer, the plume water is accumulated near the estuary, which can induce frontal instability and push the plume front closer to the shelf break where the plume can be entrained by the Alaskan Stream, thereby stimulating offshore transport. However, an earlier onset of downwellingfavorable wind (immediately following the peak river discharge) tends to generate a significant downstream transport pulse that drains the buoyancy and plume content 
from the shelf, which hinders frontal instability and reduces the offshore transport flux. As the river discharge decreases in September and October the plume shrinks, and downwelling-favorable wind events tend to induce transport pulses into PWS.

Doubling the input of freshwater not only increases the transport magnitude, but also induces more variability in the region that the plume can reach, and consequently changes the timing of various transport events as well as shifts between transport pathways (e.g. from alongshore to offshore). The impact is felt more strongly for the offshore transport as it is limited and depends highly on the interaction among different processes. The magnitude and timing of discharge, local wind, and the Alaskan Stream act together to influence the offshore transport. Thus one event may significantly change the annual budget (e.g. early September 2010). In other words, the offshore transport of the riverine input can be highly variable depending on the condition in each year. Offshore transport can also occur far downstream (west of area P), but the concentration there is low. Thus except for some extreme condition the primary offshore transport is through the offshore boundary of the plume area (i.e., transect $\mathrm{OP}$ ).

Moreover, climate change may lead to not only the glacier melt (Arendt et al. 2002; Luthcke et al. 2008) but also phonological changes (Menzel et al. 2006) of the atmospheric forcing (wind and precipitation patterns) as well as the ocean circulation. As shown above, increased discharge can enhance the accumulation rate and timing of the full growth of the plume, one would also expect the extended discharge peak might also extend the accumulation time and favors larger plume if the wind were held off 
until the fall. The changes in the wind field may have dramatic impacts on the annual cycle of the plume, as wind affects not only the accumulation and expansion of the plume, but also the termination of the plume. A longer period of relaxed wind allows more opportunity for the interaction between the plume and the offshore current system, which would favor offshore transport. The enhanced exchange between the shelf and basin could drive intense primary productivity (Schroth et al. 2009; Childers et al. 2005). Hickley et al (2009) incorporated iron into a coupled ROMS-NPZ model, and successfully distinguished coastal and oceanic ecosystem, they also found two size classes of phytoplankton discriminating the two ecosystems. Although the transport patterns were derived based on the passive tracer, they may to some degree represent the spread of iron in the NGoA as the CR is a primary source of iron (Schroth et al. 2009, Lippiatt et al. 2010). In contrast, the transport patterns for other nutrients such as nitrate may be significantly different because the concentration in the offshore water is often higher than the concentration in the estuary. Analyses for other biogeochemically active nutrients can be carried out in a follow-up study as the current model included the biogeochemical model CoSiNE. 


\section{CHAPTER 4}

\section{CONCLUSIONS}

Utilizing a three-level nested ROMS, this study illustrated for the first time the evolution of the CR plume and how it influences the along- and cross-shore transport in the NGoA. A passive tracer was introduced in the model to delineate the formation/diminishing of the plume bulge and to diagnose the spread of the CR discharge in the shelf, into PWS and offshore. Furthermore, a model experiment with doubled discharge (X2) was conducted to evaluate the effect of anticipated future scenario of increasing discharge.

Observations revealed that the CR plume is surface trapped with a mean depth of $\sim 10 \mathrm{~m}$. The model well reproduced this feature near the river mouth and also successfully captured its effect at GAK1 (far field downstream) (Figure 3.1).

Furthermore, the model revealed an apparent annual cycle of the plume, which appears to be modulated by the discharge and wind condition (Figure 3.4, 3.5 and 3.6). As the spring freshet began, the plume established in May. In 2010, moderate downwellingfavorable wind happened intermittently from June to July, which kept the plume close to the Hinchinbrook and Montague islands. The wind remained tranquil in late summer 2010 so that the buoyancy and the passive tracer were accumulated in a massive bulge adjacent to the estuary. Comparing to the $X 2$ case 2010 , the plume was able to grow even longer until the onset of the strong storm in late September. In contrast, the alongshore wind was much weaker and became eastward (upwelling-favorable) for a 
considerable amount of time in early summer of 2011 , and consequently, the plume was shallower and closer to the shelf break. Downwelling-favorable wind returned unusually early in the beginning of August 2011. Then the plume was pushed back against the shore and into PWS. An intense coastal current developed, which enhanced the downstream spread of the CR plume.

The 2010 and 2011 simulation further disclosed that the upstream (eastward) transport in the NGoA is negligibly small. It is related to the persistent westward flowing ACC, which is consistent with the result of Fong and Geyer (2002). Majority of the passive tracer released in the CR discharge is transported southwestward on the shelf, about $60 \%$ off the southern tip of the Montague Island, while about one third of the CR input goes into PWS and close to $60 \%$ of which exits PWS from Montague Strait. The rest few percent is transported across the shelf break and exported to the GoA basin. Downstream transport and the transport into PWS are highly regulated by the discharge and downwelling-favorable wind, while the offshore transport is related to the accumulation of plume water in the shelf, frontal instability and the Alaskan Stream. Previous studies usually emphasized on the plume formation (Garvine 1999) and the dynamical balance (Fong and Geyer 2002) within the plume while neglected decaying processes of the plume. This study suggested that the CR plume decays much faster than its formation, even without strong downweling-favorable wind (WR Case 2010). If the wind remains to be tranquil as in the summer 2010, the bulge continues to grow until frontal instability kicks in. These frontal features can interact with the Alaskan Stream to induce intense transport pulses across the shelf break, and they also 
propagate westward along the plume front to impact the downstream transport.

Alternatively as in 2011, a downwelling-favorable wind event in early August accelerates the southwestward coastal current and triggers an intense downstream transport event. (Figure 3.9b) Both cases result in a sudden release of the buoyancy and the plume content. Accompanied by the dwindling discharge, the plume collapses rapidly in the shelf. On the other hand, the intense alongshore transport significantly affects the water property and circulation downstream as seen at GAK1.

The double discharge case (X2) exemplified the differences that could arise from higher discharge rates projected for the future climate scenario. Not only the magnitude but also the timing of certain transport events in the X2 case changed when compared to the WR case. In particular, offshore transport could increase by several folds because it depends highly on the cooperation of the discharge, local wind, topography, and the Alaskan Stream. Synoptic weathers could alter the timing of prevailing winds relative to discharge peaks as seen in 2010 and 2011. The bigger plume in the X2 case affected different regions where the plume could reach. As the bathymetry is complicated in this area including curved coastline, restricted sound, islands and incised canyons, the flow field is highly heterogeneous. The plume appeared to be more easily entrained by the seaward flow along the side of Hinchinbrook Canyon to result in much stronger offshore transport peaks.

This perspective leads to a cautionary note on predicting the potential impacts associated with the future scenario of accelerated glacier melting. The present study adds to the understanding of how different processes including discharge, local wind, AS, 
and the topography act in concert to control the plume evolution as well as the alongand cross-shore transports of riverine materials. However, mesoscale variability both in the ocean and in the atmosphere, which remains a challenge to predict precisely, has the ability to change various transport fluxes, particularly for the offshore transport by as much as $300 \%$. A comprehensive evaluation of CR's roles in the NGoA would need to take into account as many of related factors as possible. Lastly, the ocean model is far from perfect. The topography has been smoothed, which considerably differs from the real world in key places such as the shelf break, entrances to PWS, and canyons. Tides have been excluded, and tidal mixing including the additional mixing imposed near intertidal areas can affect far downstream and off shore via the advective effect in the plume (Xue and Du 2012). Future work is needed to improve the simulation of the plume as well as to understand additional properties that are also biogeochemically active such as sediments, macro- and micronutrients. 


\section{REFERENCES}

Arendt AA, Echelmeyer KA, Harrison WD, Lingle CS, Valentine VB (2002) Rapid wastage of Alaska glaciers and their contribution to rising sea level. Science 297:382-386

Avicola G, Huq P (2003a) The characteristics of the recirculating bulge region in coastal buoyant outflows. J Mar Res 61:435-463

Avicola G, Huq P (2003b) The role of outflow geometry in the formation of the recirculating bulge region in coastal buoyant outflows. J Mar Res 61:411-434

Boyd PW, Law CS, Wong CS, Nojiri Y, Tsuda A, Levasseur M, Takeda S, Rivkin R, Harrison PJ, Strzepek R (2004) The decline and fate of an iron-induced subarctic phytoplankton bloom. Nature 428:549-553

Chao Y, Li Z, Farrara J, McWilliams JC, Bellingham J, Capet X, Chavez F, Choi J, Davis R, Doyle J (2009) Development, implementation and evaluation of a dataassimilative ocean forecasting system off the central California coast. Deep Sea Research Part II: Topical Studies in Oceanography 56:100-126

Chase Z, Strutton PG, Hales B (2007) Iron links river runoff and shelf width to phytoplankton biomass along the US West Coast. Geophys Res Lett 34:L4607

Childers AR, Whitledge TE, Stockwell DA (2005) Seasonal and interannual variability in the distribution of nutrients and chlorophyll $a$ across the Gulf of Alaska shelf: 1998-2000. Deep Sea Research Part II: Topical Studies in Oceanography 52:193216

Denamiel C, Budgell WP, Toumi R (2013) The Congo River plume: Impact of the forcing on the far-field and near-field dynamics. Journal of Geophysical Research:

Oceans

Farrara JD, Chao Y, Li Z, Wang X, Jin X, Zhang H, Li P, Vu Q, Olsson PQ, Carl Schoch G (2012a) A data-assimilative ocean forecasting system for the Prince William Sound and an evaluation of its performance during Sound Predictions 2009. Cont Shelf Res

Farrara JD, Chao Y, Li Z, Wang X, Jin X, Zhang H, Li P, Vu Q, Olsson PQ, Carl Schoch G (2012b) A data-assimilative ocean forecasting system for the Prince William Sound and an evaluation of its performance during Sound Predictions 2009. Cont Shelf Res 
Fong DA, Geyer WR (2002) The alongshore transport of freshwater in a surface-trapped river plume*. J Phys Oceanogr 32:957-972

Garvine RW (1999) Penetration of buoyant coastal discharge onto the continental shelf: A numerical model experiment. J Phys Oceanogr 29:1892-1909

Geyer WR, Signell RP, Fong DA, Wang J, Anderson DM, Keafer BA (2004) The freshwater transport and dynamics of the western Maine coastal current. Cont Shelf Res 24:1339-1357

Hallet B, Hunter L, Bogen J (1996) Rates of erosion and sediment evacuation by glaciers: A review of field data and their implications. Global Planet Change 12:213-235

Hermann AJ, Haidvogel DB, Dobbins EL, Stabeno PJ (2002) Coupling global and regional circulation models in the coastal Gulf of Alaska. Prog Oceanogr 53:335-367

Henson SA, Thomas AC (2008) A census of oceanic anticyclonic eddies in the Gulf of Alaska. Deep Sea Research Part I: Oceanographic Research Papers 55:163-176

Hickey B, Geier S, Kachel N, MacFadyen A (2005) A bi-directional river plume: The Columbia in summer. Cont Shelf Res 25:1631-1656

Hickey BM, Pietrafesa U, Jay DA, Boicourt WC (1998) The Columbia River plume study: Subtidal variability in the velocity and salinity fields. Journal of Geophysical Research: Oceans (1978-2012) 103:10339-10368

Hinckley S, Coyle KO, Gibson G, Hermann AJ, Dobbins EL (2009) A biophysical NPZ model with iron for the Gulf of Alaska: Reproducing the differences between an oceanic HNLC ecosystem and a classical northern temperate shelf ecosystem. Deep Sea Research Part II: Topical Studies in Oceanography 56:2520-2536

Kourafalou VH, Oey L, Wang JD, Lee TN (1996) The fate of river discharge on the continental shelf 1 . Modeling the river plume and the inner shelf coastal current. J Geophys Res 101:3415-3434

Ladd C, Stabeno P, Cokelet ED (2005) A note on cross-shelf exchange in the northern Gulf of Alaska. Deep Sea Research Part II: Topical Studies in Oceanography 52:667-679

Large WG, McWilliams JC, Doney SC (1994) Oceanic vertical mixing: A review and a model with a nonlocal boundary layer parameterization. Rev Geophys 32:363403 
Lippiatt SM, Lohan MC, Bruland KW (2010) The distribution of reactive iron in northern Gulf of Alaska coastal waters. Mar Chem 121:187-199

Luthcke SB, Arendt AA, Rowlands DD, McCarthy JJ, Larsen CF (2008) Recent glacier mass changes in the Gulf of Alaska region from GRACE mascon solutions. J Glaciol 54:767-777

Menzel A, Sparks TH, Estrella N, Koch E, Aasa A, Ahas R, ALM KÜBLER K, Bissolli P, Braslavská O, Briede $A$ (2006) European phenological response to climate change matches the warming pattern. Global Change Biol 12:1969-1976

Milliman JD, Meade RH (1983) World-wide delivery of river sediment to the oceans. The Journal of Geology1-21

Milly PC, Dunne KA, Vecchia AV (2005) Global pattern of trends in streamflow and water availability in a changing climate. Nature 438:347-350

Okkonen SR, Weingartner TJ, Danielson SL, Musgrave DL, Schmidt GM (2003) Satellite and hydrographic observations of eddy-induced shelf-slope exchange in the northwestern Gulf of Alaska. J Geophys Res 108:3033

Powell RD, Molnia BF (1989) Glacimarine sedimentary processes, facies and morphology of the south-southeast Alaska shelf and fjords. Mar Geol 85:359-390

Royer TC (1975) Seasonal variations of waters in the northern Gulf of Alaska. paper presented at Deep Sea Research and Oceanographic Abstracts, Elsevier.

Royer TC (1982) Coastal fresh water discharge in the northeast Pacific. Journal of Geophysical Research: Oceans (1978-2012) 87:2017-2021

Royer TC (2005) Hydrographic responses at a coastal site in the northern Gulf of Alaska to seasonal and interannual forcing. Deep Sea Research Part II: Topical Studies in Oceanography 52:267-288

Schroth AW, Crusius J, Sholkovitz ER, Bostick BC (2009) Iron solubility driven by speciation in dust sources to the ocean. Nature Geoscience 2:337-340

Stabeno PJ, Hermann AJ, Bond NA, Bograd SJ (1995) Modeling the impact of climate variability on the advection of larval walleye pollock (Theragra chalcogramma) in the Gulf of Alaska. CANADIAN SPECIAL PUBLICATION OF FISHERIES AND AQUATIC SCIENCES719-727

Stabeno PJ, Reed RK, Schumacher JD (1995) The Alaska Coastal Current: continuity of transport and forcing. J Geophys Res 100:2477-2485 
Stabeno PJ, Bond NA, Hermann AJ, Kachel NB, Mordy CW, Overland JE (2004)

Meteorology and oceanography of the Northern Gulf of Alaska. Cont Shelf Res 24:859-897

Thomas AC, Weatherbee RA (2006) Satellite-measured temporal variability of the Columbia River plume. Remote Sens Environ 100:167-178

Weingartner TJ, Danielson SL, Royer TC (2005) Freshwater variability and predictability in the Alaska Coastal Current. Deep Sea Research Part II: Topical Studies in Oceanography 52:169-191

Whitney MM, Garvine RW (2005) Wind influence on a coastal buoyant outflow. J Geophys Res 110:C3014

Xue H, Du Y (2010) Implementation of a wetting-and-drying model in simulating the Kennebec-Androscoggin plume and the circulation in Casco Bay. Ocean Dynamics 60:341-357

Yankovsky AE, Chapman DC (1997) A simple theory for the fate of buoyant coastal discharges*. J Phys Oceanogr 27:1386-1401 


\section{BIOGRAPHY OF THE AUTHOR}

Yuan Wang was born on July 1st 1987 in the scenic mountainous city Guiyang, Guizhou, China. He graduated from Guiyang No. 25 Middle School and Guiyang No. 1 High School. He completed his undergraduate studies at University of Science and Technology of China in Hefei, China with a Bachelor of Science degree in Atmospheric Science in 2010 . Then he chose to study oceanography for interest. In the same year, he came to School of Marine Sciences, University of Maine to start his Oceanography Odyssey. Under the guidance of his advisors Dr. Huijie Xue and Dr. Fei Chai, he dives in his research on the CR plume. He is a candidate for the Master of Science degree in Oceanography from the University of Maine in December, 2013. 